\title{
Is the value of travel time savings increasing? Analysis throughout a financial crisis
}

\author{
Rich, Jeppe; Vandet, Christian Anker
}

Published in:

Transportation Research. Part A: Policy \& Practice

Link to article, DOI:

10.1016/j.tra.2019.03.012

Publication date:

2019

Document Version

Early version, also known as pre-print

Link back to DTU Orbit

\section{Citation (APA):}

Rich, J., \& Vandet, C. A. (2019). Is the value of travel time savings increasing? Analysis throughout a financial crisis. Transportation Research. Part A: Policy \& Practice, 124, 145-168.

https://doi.org/10.1016/j.tra.2019.03.012

\section{General rights}

Copyright and moral rights for the publications made accessible in the public portal are retained by the authors and/or other copyright owners and it is a condition of accessing publications that users recognise and abide by the legal requirements associated with these rights.

- Users may download and print one copy of any publication from the public portal for the purpose of private study or research.

- You may not further distribute the material or use it for any profit-making activity or commercial gain

- You may freely distribute the URL identifying the publication in the public portal 


\title{
Is the value of travel time savings increasing? Analysis throughout a financial crisis
}

\author{
Jeppe Rich $\bowtie$ and Christian Anker Vandet \\ DTU Management Engineering, Technical University of Denmark \\ Bygningstorvet 16B, 2800 Kgs. Lyngby \\ هrich@dtu.dk, Phone +45 45251536
}

\author{
Cite as: $\quad$ Rich, J. and Vandet, C.A. (2019). Is the value of travel time savings increasing? Analysis \\ throughout a financial crisis. Transport Research Part A. \\ https://doi.org/10.1016/j.tra.2019.03.012
}

\begin{abstract}
In this paper we ask the question if the value of travel time savings (VTTS) is increasing over time and continue to investigate this based on a pooled cross-section model. The analysis is based on data originating from a large-scale Danish national ongoing travel survey from 2006 to 2016 consisting of more than 400,000 trips. The period is interesting from a research perspective as it offers substantial variation in income, is characterised by structural changes due to increased urbanisation and congestion and at the same time represents a phasing-in period for mobile broadband solutions from almost no coverage to full national coverage. Several things are revealed from the analysis. It is shown that the financial crisis impacts VTTS and that the impact differs across income groups. It is also found that, over the period, VTTS increases by approximately $10 \%$. Although this largely correspond to the growth in the disposable income, it is not possible to point to precise confounders and their relative importance. Rather the paper suggest that the increase in VTTS is caused by a mix of different cofounders, which include (but is not limited to) increasing travel distances, increasing congestion and increasing income.

Keywords: value-of-travel-time-savings; transport models; appraisal; forecasting; financial crisis; income effects.

\section{Introduction}

The value of travel time savings (VTTS) is an important variable in transport analysis. It measures the monetary value of travel time savings and is an integral part of transport modelling and appraisal studies. Typically, consumer benefits resulting from travel time savings due to new infrastructure or pricing policies dominate most other assessment components in the appraisal analysis as evidenced in several ex-post
\end{abstract}


studies (Elhorst and Oosterhaven, 2008; Knudsen and Rich, 2013; Quinet 2014). Due to this, it is relevant to ask the question whether VTTS can be assumed stable over time and if not, analyse such instability and the possible cause of it in more detail.

\subsection{Why VTTS could change over time - evidence from the literature}

Contrary to other model parameters, VTTS cannot be assumed constant over time. Time is a limited good and as productivity and income increase, the relative value of time increases as well (Jara-Diaz, 2002). Historically, the projection of VTTS has been closely linked to personal income growth, which in practical applications is typically approximated by GDP growth. Due to a substantial amount of uncertainty in predicting the relationship between income and VTTS, it is common to apply relatively simple "rule-ofthumb" estimates that are measured as elasticity to income. A number of studies have argued for elasticities less than unity (Algers et al., 1996; Ramjerdi et al., 1997), and this was also found in a European meta-study (Heatco, 2006) that recommended an elasticity to GDP of 0.7. Other studies argue for close to unity elasticities (Fosgerau, 2005), and this is in line with the current recommendation in the UK (WebTag, 2014). However, others have found elasticities higher than unity as presented in Douglas and Wallis (2013) for Australia and New Zeeland.

Generally, as discussed by Mackie et al. (2003), it is not clear what the elasticity should be, and from a theoretical standpoint there is no reason why the income elasticity for private travel should be unity, since it is a matter of personal preference how individuals or households allocate additional income to purchasing time savings. There can be many reasons why the average VTTS for the population could increase or decrease over time. A discussion of this is offered below.

- Wealth in general: In the extreme case where everybody is (very) rich, the marginal utility of earned income approaches zero. In this situation, because transport costs are part of the budget constraint, the preference with respect to transport costs will be weakened as well. This will cause the VTTS to increase and in particularly for those with high incomes. This is indeed a relevant argument why, in rich western countries such as Denmark and Australia, the VTTS could increase. This argument is supported by one of the most classical economic theories, namely that the marginal utility of income for a person declines with the "stock" he already has (Marshall, 1890).

- Better transport comfort: More comfortable cars and public transport services could indeed mean that the time spent in these modes of transport is less "painful". Hence, the discomfort or VTTS should decrease. This effect is confirmed in a number of studies, which find VTTS discrepancies between high-comfort public transport modes such as high-speed rail and low-comfort modes such as buses $^{1}$ (Wardman, 2004).

- Mobile broadband and communication technology: In the "old" days, before 2005, people used to read books and newspapers while travelling in public transport. Nowadays, there are more opportunities and it is possible to respond to emails and work while travelling. For car users, it is also possible to talk while driving (handheld communication and Bluetooth) and all of this points in the direction of a lower VTTS simply because transport becomes less of a waste of time (Deloitte, 2015). However, at the same time it could also be argued that all of these opportunities may have

\footnotetext{
${ }^{1}$ Many studies also find the opposite and this is typically due to income or travel distance effects not being accounted for.
} 
an effect on the value of leisure time which could neutralise, at least partly, the possible increase in VTTS (King, 2014).

- Congestion and urbanisation: If we look beyond the fact that new technologies may partly provide some relief in how travel time is perceived, congestion will point in the other direction. This is the case for cars but certainly also for public transport. In fact, congestion is an increasing concern due to the escalation in urbanisation in most cities around the world. Even in Denmark, which has a relative well-functioning public transport system around Copenhagen, there is little chance of being productive while travelling in the morning peak as all trains and busses are typically fully packed. For cars, it has long been recognised that congestion time is more costly than free flow time (Small et al., 1999; Fosgerau et al., 2007; Hensher, 2011). This is partly due to comfort elements but also because travel-time variability and the risk of being late is a function of congestion as well. So, while we are still waiting for autonomous cars, which might lead to less stressful driving in congested networks, we should see an increasing VTTS as a function of congestion.

- Travel time: In Denmark there has in recent decades been a clear tendency to longer trips. The trend is likely caused by a combination of confounding factors, such as better cars and comfort, labour market specialisation and changed urbanisation and migration patterns. However, it is beyond doubt that longer travel times will lead to a higher VTTS (Daly, 2010; Daly and Carrasco, 2009; Abrantes and Wardman, 2011).

One way of analysing the combined effect of all of these underlying explanations is to formulate a large controlled design that incorporates all the possible attributes and repeat this for different time periods. However, this is a costly and difficult approach and would suffer from the short-comings of SP studies (Abegaz et al. 2017; Bates, 1994). Recently in Zheng et al. (2018), it is demonstrated that the design of the SP have a significant impact on the VTTS. In the paper they also demonstrate how proper pivoting can be a mean to reduce the dependency of the design. Another common approach is that of Meta studies (Abrantes and Wardman, 2011) which compile the results of many studies and attempts to draw generic conclusions across these studies. The challenge of meta studies is that many VTTS studies are not strictly comparable, which requires care when compiling data and interpreting results. Yet another approach is to reveal the VTTS from a large uncontrolled pooled cross-section model which essentially just mimics the preferences of the population at different time periods. This is the approach recommended by Mackie et al. (2003) and also applied in this paper. It should be noted that although the forecasting of VTTS is often used in the transport appraisal community, the transport modelling community is equally dependent on the ability to forecast VTTS as such changes will influence the balance between cost and time in the demand models. Considerations about how such changes should be incorporated are considered in (Gunn, 1983) and (Gunn, 2001).

The approach taken in this paper resembles what is referred to as pooled cross-sectional modelling (e.g., Wooldridge, 2002). By having access to a large RP dataset (from 2006 to 2016) and combining these data with historical level-of-service data, which have been calculated from back-casting experiments with the Danish National Model (Rich and Hansen, 2016), inter-temporal as well as intra-temporal variations in VTTS, can be estimated (Shires and de Jong, 2009). The modelling period is characterised by substantial variation in income (due to the years of financial crisis), substantial variation in fuel prices due to the "third" oil crisis, increasing congestion due to an accelerated urbanisation in Denmark and finally, the phasing-in of mobile 
broadband technology which has evolved from a negligible level (speed and market share combined) to an almost full $4 \mathrm{G}$ coverage.

Contrary to SP studies where confounding factors to some extent can be revealed from controlling the design, this is more difficult in RP studies. In other words, although we are able to indicate an upward trend in VTTS, we are generally not able to precisely disentangle the relative magnitude of different factors. One challenge is to measure income effects when income is a known driver of many other variables. However, what a pooled cross-section model offers in contrast to SP studies, is the revelation of how dynamic changes in the composition of the population, its location, the infrastructure and other external effects may led to a change in the perception of VTTS across the population.

In Section 2 we present the model framework and the econometric specification. In Section 3 we consider the data including a descriptive presentation of the survey data and a presentation of the level-of-service data. In Section 4 we present results including model estimation, analysis of the revealed VTTS estimates and its variation (based on bootstrapping) and a discussion of confounding variables. Finally, in Section 5 , we summarise and offer concluding remarks.

\section{Model formulation}

The primary objective of the paper is to address the issue of VTTS stability on the basis of pooled crosssection time series models for the choice of transport mode. Consequently, the econometric modelling is carried out as a sequence of discrete choice models in the time domain, with VTTS inferred directly from the model. The models are estimated on the basis of trip diary data from an ongoing national survey and the data resemble unrelated repeated cross-sections and does not constitute a panel structure. In order to estimate trade-offs between time and cost across modes, attributes for travel time and cost for all mode alternatives at all times are applied in the model. These data are available from detailed route-choice models for walk, bike, cars and public transport.

The VTTS represents the amount of money a given individual $n$ is willing to pay in order to save a unit of travel time. It can be revealed from a discrete choice model for the choice of mode $m$ where the indirect utility function $V_{n}(m)$ as shown in equation (1) includes travel time $t$ and travel cost $c$ through parametric functions represented by $g\left(\beta_{t}, t\right)$ and $f\left(\beta_{c}, c\right)$

(1) $\quad V_{n}(m)=k_{m}+g\left(\beta_{t}, t_{n m}\right)+f\left(\beta_{c}, c_{n m}\right)+\gamma z_{n, m}+e_{n, m}, \forall n, m$

The VTTS can then be derived as in equation (2) below (Gaudry et al., 1989).

(2) $\quad \operatorname{VoT}_{n}(m)=\frac{\partial V_{n}\left(t_{n m}\right) / \partial t_{n m}}{\partial V_{n}\left(c_{n m}\right) / \partial c_{n m}}=\frac{\partial g\left(\beta_{t}, t_{n m}\right) / \partial t_{n m}}{\partial f\left(\beta_{c}, c_{n m}\right) / \partial c_{n m}}$

It is clear that time and cost depend on the mode of transport as well as the individual if the functional form differs from a strict linear model.

In order to estimate the VTTS over time we carry out repeated cross-section estimations. In this way we are able to assess time and cost preferences from one period to another. As pointed out in Wooldridge (2002), every method that applies to pure cross-section analysis can be applied to pooled cross-sections. However, 
in order to account for aggregate systematic changes over time it is necessary to include time period dummies as well as combined socio-economic variables and time dummies.

Rather than estimating models for single years, the estimation is carried out for ten "year clusters" of three consecutive years. Each cluster is referred to as $y=1, \ldots, Y$ and indirect utility functions (Ben-Akiva and Lerman, 1985) now reflect utility for individual $n$ in a given cluster $y$, e.g. $V_{n, 1}(m), \ldots, V_{n, y}(m), \ldots, V_{n, Y}(m)$. Hence, the first cluster covers the period from 2006-2008, the next cluster the period from 2007-2009 whereas the last cluster covers the period from 2014-2016. This causes the estimated values for a given cluster to represent an average over three consecutive years. In other words, the estimated values essentially represent a moving average. The benefit of this approach is that we have more data available for the estimation of the different models and in particular for the estimation of the correlation between income and the VTTS. Another desirable effect is that the VTTS, due to the underlying lag effect, becomes smoothed over time. It has been verified that conclusions are not affected by applying an alternative clustering of 2 years and that the clustering indeed works as a "smoother".

As discussed in the introduction there is strong empirical evidence for positive correlation between income and the VTTS: The higher the income the higher the VTTS. However, we need to distinguish between two different effects in the following: i) inter-temporal effects of increasing income over time and ii) intratemporal effects that reflect heterogeneity across a population. Empirically, income and VTTS correlate differently when measured from an inter-temporal perspective compared to a cross-sectional perspective, that is, intra-temporally. The latter is typically found to be lower than the inter-temporal elasticities. If anything, it suggests that there are elements in long-term VTTS estimates which are not well captured in a cross-section analysis. Mackie et al. (2003) acknowledge this and suggested that those with higher incomes (or lower incomes) could have an inherently different attitude towards money. Additionally and more importantly, the problem of inferring elasticities from a pure cross-sectional perspective is that we eliminate the effect of potentially confounding factors that evolve over time and are partly correlated with income. One example is that the combination of higher incomes and urbanisation leads to increasing housing prices which infer a relocation process where people trade cheaper houses outside the city for longer travel distances. This in turn leads to more congestion and over time the combined effect is likely to increase VTTS (Daly and Carrasco, 2009).

The work-horse for the analysis is a discrete choice model for the choice of mode $m$ belonging to a choiceset $M_{n}$. The choice-set is specific to the respondent in order to restrict persons without a driver's license from being a car driver. To be able to reveal both intra-temporal and inter-temporal effects we consider, for each cluster $y$, differences in the VTTS over different income groups by using an indicator approach. We estimate $J$ separate cost-parameters $\beta_{c 1}, \ldots, \beta_{c J}$ for $J$ different income groups for each cluster. Hence,

$$
\begin{aligned}
V_{n, y}(m)= & k_{m, y}+\beta_{t, y} g\left(t_{n, m, y}\right)+\sum_{j=1}^{J}\left[\beta_{c, j, y} 1_{n}(j, y) f\left(c_{n, m, y}\right)\right] \\
& +\boldsymbol{\theta} \mathbf{z}_{n, m, y}+\epsilon_{n, m, y}, \forall n, m \in M_{n}, y=1, \ldots, Y
\end{aligned}
$$

In equation (3) $1_{n}(j, y)$ represent an indicator function such that $1_{n}(j, y)=1 \Leftrightarrow n$ belongs to income group $j$ in cluster $y$ whereas $1_{n}(j, y)=0 \Leftrightarrow n$ does not belong to income group $j$ for cluster $y$. In addition 
to time $t_{n, m, y}$ and cost $c_{n, m, y}$ variables a number of additional variables $\boldsymbol{\theta} \mathbf{z}_{n, m, y}$ have been included in order to account for car ownership status, mode and cluster specific constants, urban areas, parking costs and other variables (Appendix D). We consider four income groups which are defined according to empirical quartiles, hence, income group 1 represents the $25 \%$ individuals with the lowest annual personal income whereas group 4 represents the $25 \%$ individuals with the highest incomes. The benefit of the indicator approach is that we assume very little about the model structure but simply reveal preferences for the different quartiles.

Due to the clustering of years, error terms $\epsilon_{n, m, y}$ are correlated across $y$. It would require a robust covariance estimator if common parameters were estimated across $y$. However, in our case we consider each cluster as an entirely self-contained model which does not share parameters across clusters. It means that preferences across clusters, as represented by model parameters, will be consistent and efficient for each cluster. However, the clustering obviously implies that the model parameters are correlated due to the moving average, which in turn causes the VTTS to be correspondingly smoothed. The inter-temporal VTTS variation can be investigated by comparing the average values between time periods and for different income groups.

The expected VTTS for person $n$ at time period $y$ can be calculated as the weighted mean across modes as shown in (4) below.

$$
E\left[\operatorname{VTTS}_{n, y}\right]=\sum_{m \in M_{n}} P_{n, y}(m)\left(\sum_{j=1}^{J} 1_{n}(j) \frac{\partial g\left(\beta_{t, y}, t_{n, m, y}\right) / \partial t_{n, m, y}}{\partial f\left(\beta_{c, j, y}, c_{j, n, m, y}\right) / \partial c_{j, n, m, y}}\right), \forall n, y
$$

$P_{n, y}(m)$ refers to mode choice probabilities and the differentiation of $g$ and $f$ follows from equation (2). As income is allowed to differ between individuals, $E\left[V_{T T S} S_{n, y}\right]$ also represent income variation for the different income groups $j=1, \ldots, J$. It should be noted that $m$, in this context, represents only motorised modes, as walk and bike have been considered as modes with only time parameters which has been estimated separately. In other words, although walk and bike are included in the model, VTTS is not calculated for these. For a given income group $j$ we define the inter-temporal variation as;

(5) $\quad Q(j)=\left(V o T_{y=1, j}, V o T_{y=2, j}, \ldots, V o T_{y=Y, j}\right), \forall j=1, \ldots, J$

which can be normalised with respect to $V o T_{y=1, j}$ in order to reveal relative growth during the period. The intra-temporal variation on the other hand, reflects the variation across individuals for a given cluster $y$ and is given by;

(6) $\quad H(y)=\left(V o T_{y, j=1}, V o T_{y, j=2}, V o T_{y, j=3}, V o T_{y, j=4}\right)$

As seen, from the model in equation (4) we estimate a generic VTTS across different modes and trip purposes with the exception that we do not include business trips. Business trips are known to have a significantly higher VTTS and are generally not comparable to other trip purposes. There are several reasons why we estimate a generic VTTS rather than specific values for different modes and different purposes. Firstly, the aim of our analysis is to capture generic long-term patterns rather than specific mode and purpose variations. Secondly, even if fluctuations across mode and purpose exist, it will not affect the overall conclusion of the paper, as these changes will be absorbed in the average VTTS. 
According to a previous Danish VTTS study (Fosgerau, 2007; TRM, 2015), the variation across trip purposes and modes was found to be small. Also note that, although by assumption, we presume $\beta_{t, y}$ to be generic across $m$, it is still possible to reveal VTTS variation across mode (and trip purposes) to the extent this is caused by differences in travel time and cost or other exogenous variables embedded in the model (refer to Appendix A).

\subsection{Scope of analysis and limitations}

The investigation of dynamic preferences, such as the value-of-time, is a challenging task. A main challenge is to rigorously address all relevant confounding factors for the VTTS but also to filter out certain effects from the others. In Table 1 we provide an overview of possible influential factors and to what extent these are included in the analysis.

\begin{tabular}{|c|c|c|}
\hline Factors explaining VTTS & Included & Non included \\
\hline Infrastructure & $\begin{array}{l}\text { Included by adapting historical } \\
\text { infrastructure and calculating LoS }\end{array}$ & \\
\hline Income and demography & Included entirely & \\
\hline Migration and job location & Included entirely & \\
\hline Car ownership & Included but only "exogenously" & \\
\hline Transport cost & $\begin{array}{l}\text { Is included but only in the form of } \\
\text { changes in marginal cost }\end{array}$ & \\
\hline Technology changes & & Is not included \\
\hline Comfort changes and congestion & $\begin{array}{l}\text { Is partly included but only } \\
\text { through measures of } \\
\text { "congestion" and not perceived } \\
\text { comfort }\end{array}$ & \\
\hline Other preference changes & & $\begin{array}{l}\text { Is not included. Specifically, } \\
\text { possible changes (over time) in } \\
\text { how different time components } \\
\text { are perceived are not modelled }\end{array}$ \\
\hline $\begin{array}{l}\text { Mode and trip purpose } \\
\text { fluctuations }\end{array}$ & $\begin{array}{l}\text { Included to the extent this is } \\
\text { caused by level-of-service } \\
\text { fluctuations }\end{array}$ & Business trips not included \\
\hline
\end{tabular}

Table 1: Potential factors explaining VTTS that are included in the study.

The assumption of fixed weights for different time components (also refer to Table 2) could in principle distort the results, however, only to the extent these weights changes over time. Many studies have found relative stable congestion weights over time as evidenced for Denmark (Fosgerau et al., 2007; TRM, 2015a; 2015b).

The question is if underlying mode and trip purpose fluctuations could distort the results. Firstly, for trip purposes, these patterns are surprisingly stable over time and with business trips excluded from the analysis such effect should be small. Mode specific fluctuations will be captured and absorbed in the weighted average VTTS and as long as we are interested in general VTTS effects distortion should be minimal.

Even if the paper addresses many of the relevant factors, it is a challenge disentangling the different effects from one another. In other words, although the paper suggest that structural changes in the form of 
increasing travel time and increasing congestion seems to be a main driver of increasing VTTS, it is clear that such effects, at least partially, is linked to other confounders. Also, it may be difficult to filter out the effect of income from such effects.

\section{Data}

The main data sources applied in the estimation is a large Danish trip diary (Christensen and Skougaard, 2015) which has been collected since 1992 and exists in a coherent form from 2006 to the present date. The sample represents approximately 400,000 trips for which information about mode, departure time, arrival time and origin and destination is collected. From a mode choice perspective it is important to acknowledge dependencies in out-bound and home-bound transport modes and we therefore apply a tourbased model.

After preparing the data for estimation, more than 165,000 unique journeys are available for estimation. The distribution of the number of observations across years, year clusters and modes is presented below in Figure 1.

As seen, there is total of 6 modes of which car as driver (CD), taxi and public transport (Pub) are the only transport modes with cost variables. Hence, we do not assume cost-sharing among car drivers and passengers. The income represents annual personal income before tax as asked for in the TU survey. These values are all represented in fixed 2017 prices. As a relatively significant number of people have not provided income information (around 25\%), we have used imputation for these non-responses. This is based on a Hot-Deck imputation approach where the income of comparable donors is used for imputation. In 5\% of the cases it was not possible to find a sufficiently good donor and these individuals were thus removed from the data. The imputation is likely to slightly underestimate the variation in income, however, overall there is a rather good correspondence between the TU income and the register based income.

As seen from the data, there is a substantial variation in the number of observations from year to year. This relates to oversampling in selected years to support the estimation of the Danish national model (Rich and Hansen, 2016). As appears from Section 4 there is no year cluster with less then 25,000 observations. 

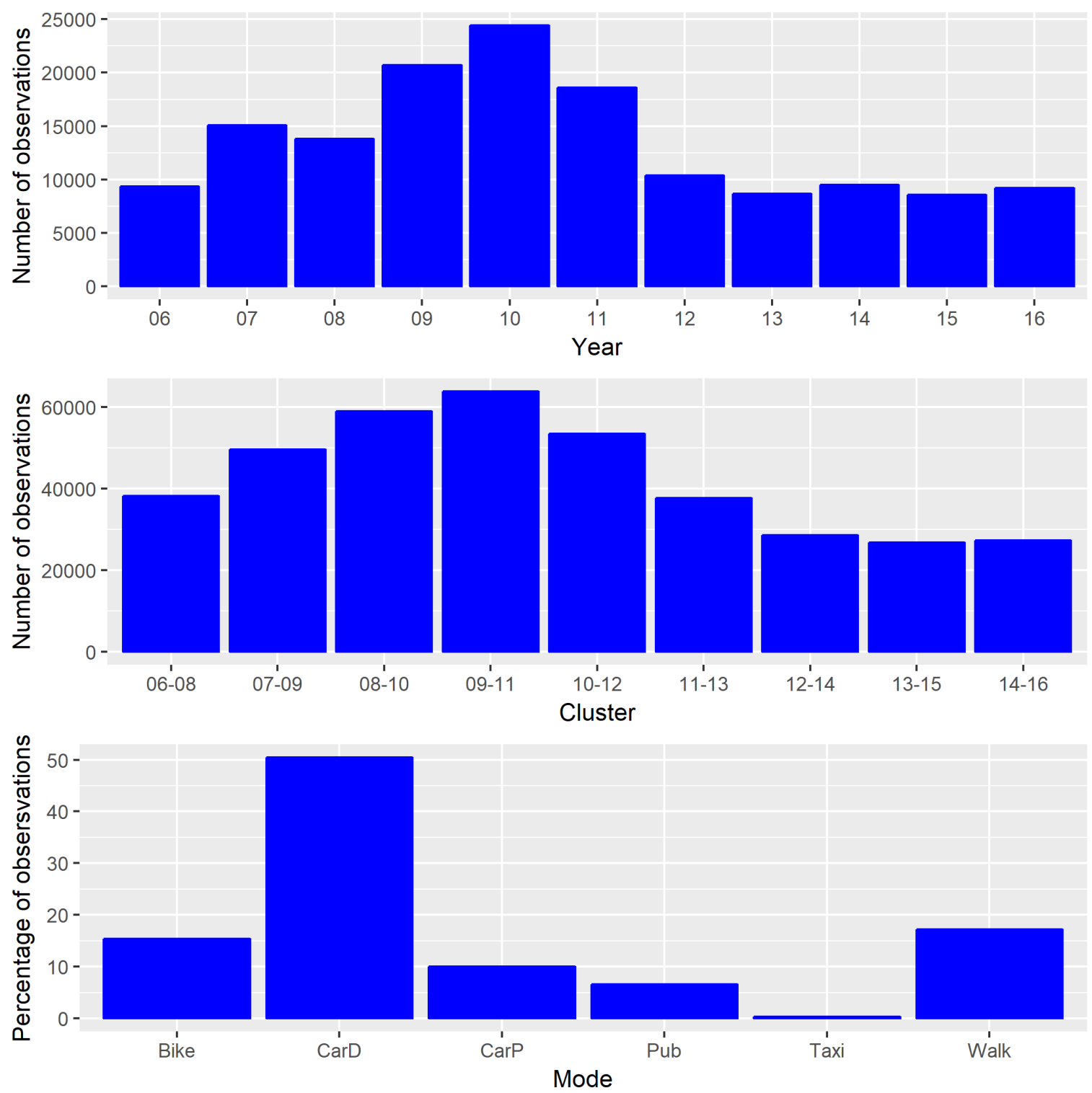

Figure 1: Observations across years.

\subsection{Level-of-service data}

In the estimation we have used level-of-service data which have been extracted from the Danish National model (Rich and Hansen, 2016). These data have been provided on a zone-to-zone basis for the different networks. Depending on the corresponding modes, travel time is constructed as a weighted sum of a number of different level-of-service variables. 
Time for cars (and passengers) as shown in (7) is a combination of free-flow time $\boldsymbol{f} \boldsymbol{f t} \boldsymbol{t}_{\boldsymbol{c a r}}(\boldsymbol{d})$, congestion time $^{2} \boldsymbol{c t} \boldsymbol{c}_{\boldsymbol{c a r}}(\boldsymbol{d})$, ferry sailing time $\boldsymbol{f} \boldsymbol{s} \boldsymbol{t}_{\boldsymbol{c a r}}(\boldsymbol{d})$, ferry waiting time $\boldsymbol{f} \boldsymbol{w} \boldsymbol{t}_{\boldsymbol{c a r}}(\boldsymbol{d})$ and early departure time $\boldsymbol{e a t}_{\boldsymbol{c a r}}(\boldsymbol{d})$. All of these attributes are calculated in the road assignment model.

$$
\operatorname{time}_{\text {car }}(d)=\left[f f t_{c a r}(d)+\gamma_{1} c t_{c a r}(d)\right]+\gamma_{2} f s t(d)+\gamma_{3} f w t(d)+\gamma_{3} e a t(d)
$$

Public transport level-of-service is calculated in a schedule-based assignment model and consists of three weighted components, in vehicle time $I n v_{p u b}(d)$, number of transfers $n s_{p u b}$ and waiting time $w t_{p u b}$ (Wardman, 2004).

$$
\text { (8) } \operatorname{time}_{p u b}(d)=I n v_{p u b}(d)+\vartheta_{1} n s_{p u b}+\vartheta_{2} w t_{p u b}
$$

Travel time bike is estimated on the basis of a bicycle network model, whereas walk is based on walking speed for different user groups.

Rather than estimating the VTTS for different time components, we have superimposed pre-defined weights which have been based on a previous VTTS study (Fosgerau, 2007) as shown in Table 2. Several studies over the years have estimated the VTTS to be higher for congestion time as compared to free travel time (Small et al., 1999; Hensher, 2011; Abrantes and Wardman, 2011).

\begin{tabular}{lll} 
Variable & Parameter & Value \\
\hline Congestion time & $\gamma_{1}$ & 1.5 \\
Ferry sailing time & $\gamma_{2}$ & 0.8 \\
Ferry waiting time & $\gamma_{3}$ & 0.8 \\
Ferry early departure time & $\gamma_{3}$ & 1 \\
Shift penalty & $\vartheta_{1}$ & 6 \\
Waiting time & $\vartheta_{2}$ & 1.5 \\
\hline
\end{tabular}

Table 2: Scaling factors for specific time components.

It means that VTTS revealed in this paper can be interpreted as a weighted VTTS over these different time components. As these weights are relative stable over time as considered in Section 2.1 and our main objective is to look at changes over time this is not considered a critical assumption for the analysis.

For simplicity, bike and walk level-of-service all refer to the 2010 baseline. As network effects and congestion are of less importance for these modes, this is not considered critical. However for car modes and public transport an interpolation of level-of-service has been used. It has not been possible to construct a fully representative public transport schedule for each year and likewise not a fully representative road network. Due to this we have calculated level-of-service for three consecutive years, 2002, 2010 and 2015, respectively. We have then, for each OD pair in the level-of-service matrices, assumed a linear interpolation between the past and the future. Hence, for a given year a level-of-service matrix is defined as

\footnotetext{
${ }^{2}$ The extra time that is caused by congestion.
} 


$$
\begin{array}{r}
T T_{\text {now }}=T T_{\text {backwards }}\left(1-\frac{\text { Year }_{\text {now }}-\text { Year }_{\text {Backwards }}}{\text { Year }_{\text {forward }}-\text { Year }_{\text {Backwards }}}\right) \\
+T T_{\text {forward }}\left(1-\frac{\text { Year }_{\text {forward }}-\text { Year }_{\text {Now }}}{\text { Year }_{\text {Forward }}-\text { Year }_{\text {Backwards }}}\right)
\end{array}
$$

From this it follows that for the year $2006, T T_{2006}$ is equal to

$$
\begin{aligned}
T T_{2006} & =T T_{2002} *\left(1-\frac{2006-2002}{2010-2002}\right)+T T_{2010} *\left(1-\frac{2010-2006}{2010-2002}\right) \\
& =T T_{2002} * 0.5+T T_{2010} * 0.5
\end{aligned}
$$

This leads to an equal weighting between level-of-service matrices from 2002 and 2010.

The fact that we consider interpolated level-of-service data is not considered critical. In fact, introducing true year-by-year matrices might result in local or regional temporal "jumps" which from a long-term perspective is not preferable.

Whereas travel time to some extent is affected by congestion, it is also affected by how the population locate from year to year. Hence, if people are trading longer travel times for cheaper houses outside the city, this is captured in the model. In other words, for level-of-service we capture both long-term structural effects as well as fluctuations to the extent these are captured by the interpolation approach. For other variables such as cost variables and income these are represented for each year. Below in Figure 2 we present the variation in selected input variables for car drivers.

As can be seen in Figure 2 and as previously commented, travel time and congestion are increasing over time. This is mainly caused by structural changes in the sense that people over time relocate with respect to residential location and job location. However, it is also partly related to increased congestion. The average travel cost is a function of distance, fuel prices and fuel efficiency. We have applied standard kilometre cost values based on values from the Ministry of Finance, which include all of these elements for all years. Hence, improved car efficiency and changes in the car stock due to changes in taxation schemes are accounted for. As regards income, the financial crisis is visible with a dip between 2008 and 2015. Hence, although the crisis started in 2007 there was a lag effect before it fully matured. In Figure 3 we consider the corresponding variation in public transport attributes. 

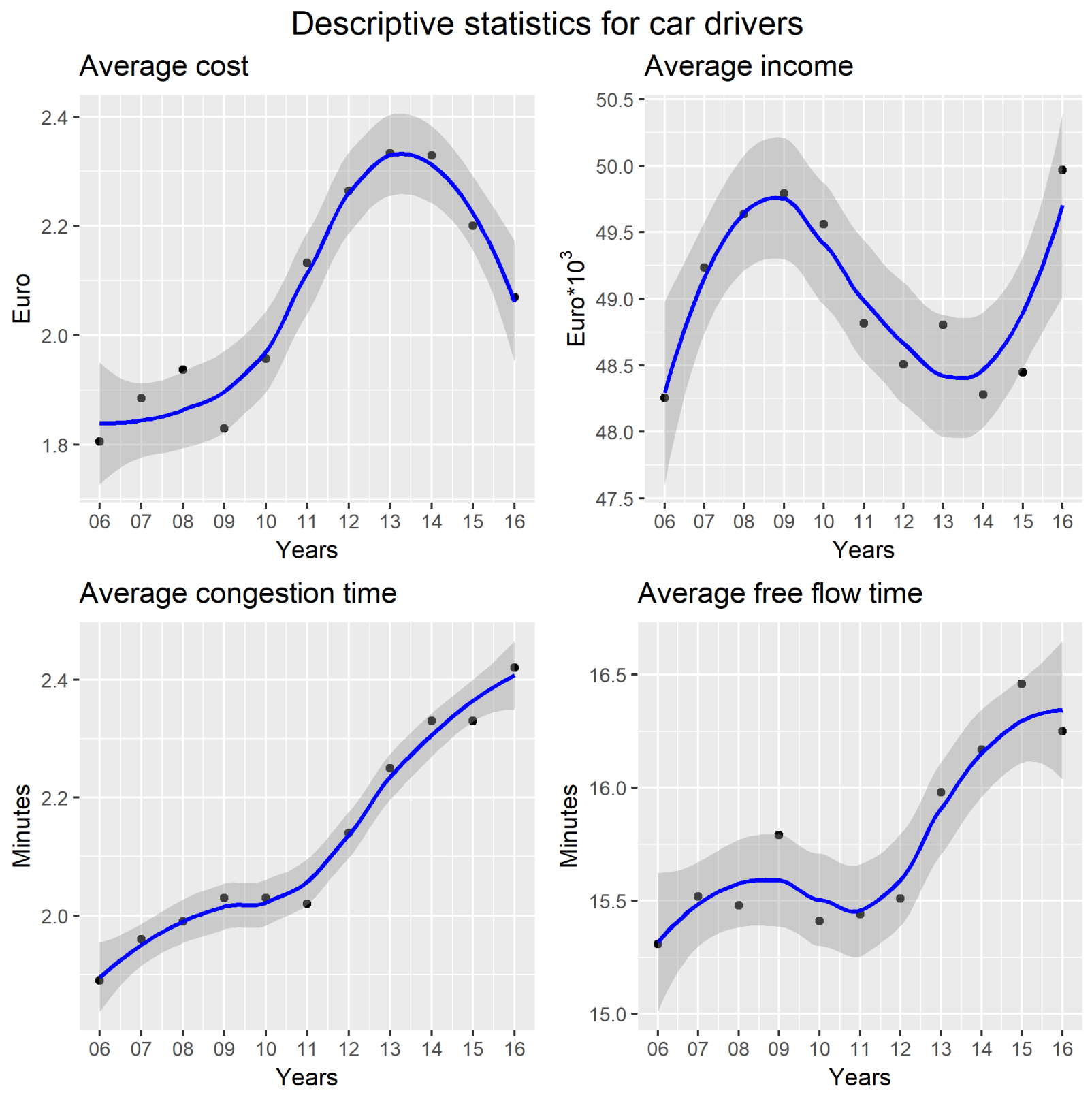

Figure 2: Inter-temporal attribute variation for car users. 


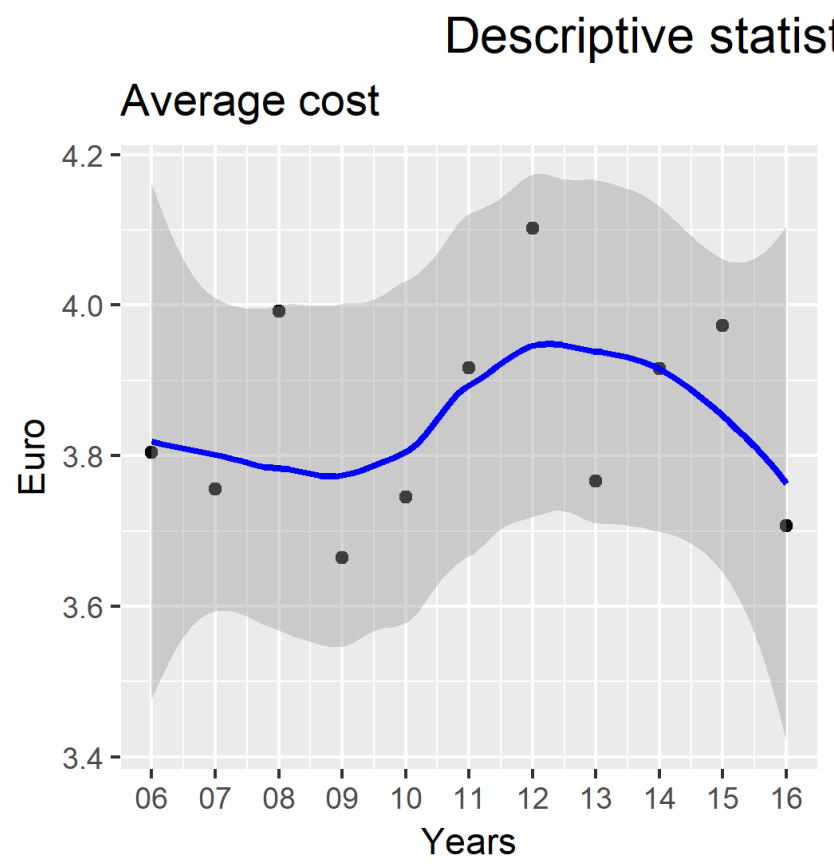

Average travel time


Figure 3: Inter-temporal attribute variation for public transport users.

In Figure 3 some of the same variation as for car are observed. That is, longer travel time (structural changes) including both free-flow (e.g. on-board time) and generic average time. Interestingly, however, the income distribution is less affected by the crisis, although it does stagnate during the crisis. This is likely the result of structural effects and the fact that the two segments are fundamentally different. Rich people may migrate to the cities where house prices are higher and the public transport service is more developed. Poorer people, on the other hand, could migrate outside the city where public transport is scarcer. Public transport prices are largely constant throughout the period, which was also expected as public transport providers are not allowed to increase their fares beyond the rate of inflation. 


\section{Results}

In the following section we consider model estimation and the estimated VTTS values in more detail. Model estimation is considered in Section 4.1. In Section 4.2 it is considered how VTTS change over time and the variance is investigated by mean of booth-strapping. Then in Section 4.3 we consider how VTTS varies with different confounding factors such as travel distance, income and congestion.

\subsection{Model estimation}

The functional form for cost and time, that is function $g\left(t_{n, m, y}\right)$ and $f\left(c_{n, m, y}\right)$ in equation (3), has been based on rigorous testing with the simple linear model constituting a natural reference model. It is widely recognised that the specific functional form will affect the formula for VTTS, which, if derived under linear time and cost functions, becomes simply the ratio of the two parameters (Gaudry et al., 1989). Empirically, there is evidence for rejecting the linear model. Daly (2010) investigates a number of studies and concludes that there is strong evidence for an increasing VTTS as a function of travel distance. Clearly, this is not accommodated in the simple linear specification as it requires a "damping" of the cost coefficient as the distance increases. In the literature this is referred to as "cost damping" and described in Rich and Mabit (2016) and Daly (2010). In this paper, two cost-damping specifications are tested: Firstly, a strict logarithmic form that represents a maximum damping pattern and secondly, a hybrid-form (Daly, 2010) that allows testing different damping degrees from an "undamped" linear specification to a maximum damped logarithmic specification.

In the model estimation, it was found that the superior model across all specifications for both cost and time was a pure logarithmic model for both variables as shown below in (11). A goodness-of-fit heat-map is offered in Appendix C. This model implies damping in cost as well as for time. As can be evidenced from Table 3 this has led to a model specification that is well-identified for all relevant parameters but also a model specification which facilitates increasing VTTS as a function of travel distance. The fact that we apply the same model for all clusters has the benefit of minimising bias that may result from applying a different model for different clusters. It has been tested that results are not sensitive to functional forms such as Box-Cox functions and hybrid forms where $\gamma$ is close to 0 .

$$
\begin{aligned}
V_{n, y}(m)= & k_{m, y}+\beta_{t, y} \ln \left(t_{n, m, y}\right)+\sum_{j=1}^{J}\left[\beta_{c, j, y} 1_{n}(j, y) \ln \left(c_{n, m, y}\right)\right] \\
& +\boldsymbol{\theta} \mathbf{z}_{n, m, y}+\epsilon_{n, m, y}, \forall n, m \in M_{n}, y=1, \ldots, Y
\end{aligned}
$$

The resulting log-log function facilitates VTTS heterogeneity with respect to time and cost and accommodates indirectly effects related to changed travel distance and time use. Below in Table 3 we present selected model parameters from the final specification (refer to Appendix D for a full parameter

\begin{tabular}{|c|c|c|c|c|c|c|c|c|c|}
\hline Parameter & $06-08$ & $07-09$ & $08-10$ & $09-11$ & $10-12$ & $11-13$ & $12-14$ & $13-15$ & $14-16$ \\
\hline Log travel time & $\begin{array}{l}-0.9396 \\
(0.0325)\end{array}$ & $\begin{array}{l}-0.9111 \\
(0.0278)\end{array}$ & $\begin{array}{l}-0.9426 \\
(0.0272)\end{array}$ & $\begin{array}{l}-0.9169 \\
(0.0261)\end{array}$ & $\begin{array}{l}-0.9369 \\
(0.0292)\end{array}$ & $\begin{array}{l}-0.9444 \\
(0.0338)\end{array}$ & $\begin{array}{l}-1.0133 \\
(0.0421)\end{array}$ & $\begin{array}{l}-1.0798 \\
(0.0444)\end{array}$ & $\begin{array}{l}-0.9969 \\
(0.0427)\end{array}$ \\
\hline $\begin{array}{l}\text { Travel time } \\
\text { (walk/bike) }\end{array}$ & $\begin{array}{l}-0.1157 \\
(0.0017)\end{array}$ & $\begin{array}{l}-0.1113 \\
(0.0013)\end{array}$ & $\begin{array}{l}-0.1142 \\
(0.0013)\end{array}$ & $\begin{array}{l}-0.1121 \\
(0.0011)\end{array}$ & $\begin{array}{l}-0.1149 \\
(0.0013)\end{array}$ & $\begin{array}{l}-0.1143 \\
(0.0015)\end{array}$ & $\begin{array}{l}-0.1182 \\
(0.0020)\end{array}$ & $\begin{array}{l}-0.1189 \\
(0.0022)\end{array}$ & $\begin{array}{l}-0.1155 \\
(0.0020)\end{array}$ \\
\hline
\end{tabular}
list). 


\begin{tabular}{llllllllll} 
Log cost (Q1) & $-0.4604)$ & -0.4720 & -0.4572 & -0.4697 & -0.4783 & -0.4969 & -0.4836 & -0.4353 & -0.4543 \\
& $(0.0186)$ & $(0.0163)$ & $(0.0151)$ & $(0.0143)$ & $(0.0156)$ & $(0.0185)$ & $(0.0221)$ & $(0.0230)$ & $(0.0225)$ \\
Log cost (Q2) & -0.4280 & -0.4205 & -0.4093 & -0.4090 & -0.4177 & -0.4352 & -0.4515 & -0.4195 & -0.4142 \\
& $(0.0192)$ & $(0.0169)$ & $(0.0155)$ & $(0.0145)$ & $(0.0156)$ & $(0.0190)$ & $(0.0229)$ & $(0.0233)$ & $(0.0226)$ \\
& -0.3754 & -0.3726 & -0.3560 & -0.3548 & -0.3717 & -0.3981 & -0.4147 & -0.3778 & -0.3559 \\
Log cost (Q3) & $(0.020)$ & $(0.0175)$ & $(0.0161)$ & $(0.0152)$ & $(0.0163)$ & $(0.0193)$ & $(0.0231)$ & $(0.0243)$ & $(0.0239)$ \\
& & & & & & & & & \\
Log cost (Q4) & -0.2865 & -0.3059 & -0.2752 & -0.2843 & -0.2922 & -0.3790 & -0.3581 & -0.3298 & -0.3305 \\
& $(0.0210)$ & $(0.0184)$ & $(0.0168)$ & $(0.0161)$ & $(0.0173)$ & $(0.0208)$ & $(0.0249)$ & $(0.0262)$ & $(0.0251)$ \\
Parking cost & -0.0996 & -0.1092 & -0.1118 & -0.1060 & -0.1053 & -0.1040 & -0.1141 & -0.1091 & -0.1058 \\
& $(0.0074)$ & $(0.0066)$ & $(0.0062)$ & $(0.0060)$ & $(0.0065)$ & $(0.0075)$ & $(0.0085)$ & $(0.0087)$ & $(0.0088)$ \\
\hline Nobs & 38014 & 49322 & 58630 & 63443 & 53154 & 37511 & 28425 & 26668 & 27200 \\
$\ell(0)$ & -68112 & -88373 & -105051 & -113675 & -95239 & -67211 & -50931 & -47783 & -48736 \\
$\ell$ & -38209 & -49890 & -59545 & -64656 & -53819 & -37742 & -28110 & -26231 & -26933 \\
$\delta^{2}$ & 0.439 & 0.435 & 0.433 & 0.431 & 0.435 & 0.438 & 0.448 & 0.451 & 0.447 \\
\hline
\end{tabular}

Table 3: Selected model parameters for all year clusters. Log cost (Q1) represents the cost parameter for income quartile 1. Numbers in parenthesis represent standard errors.

As seen from Table 3, all parameters are estimated with low standard errors for the parameters, and identification problems have not been a concern although it is based on revealed preference data. In addition to the presented attributes, a large number of additional variables have been included in the model. This includes dummy variables that relate to age, urbanisation, car ownership and mode.

Specifically, for both car drivers and car passengers two car ownership status variables have been included, one variable for households with one car, and another variable for households with more than one car. All of these variables are included in Appendix D.

\subsection{VTTS development and bootstrapping}

Below the estimated VTTS estimates are shown in Figure 4 and Table 4 for the final log-log model. 


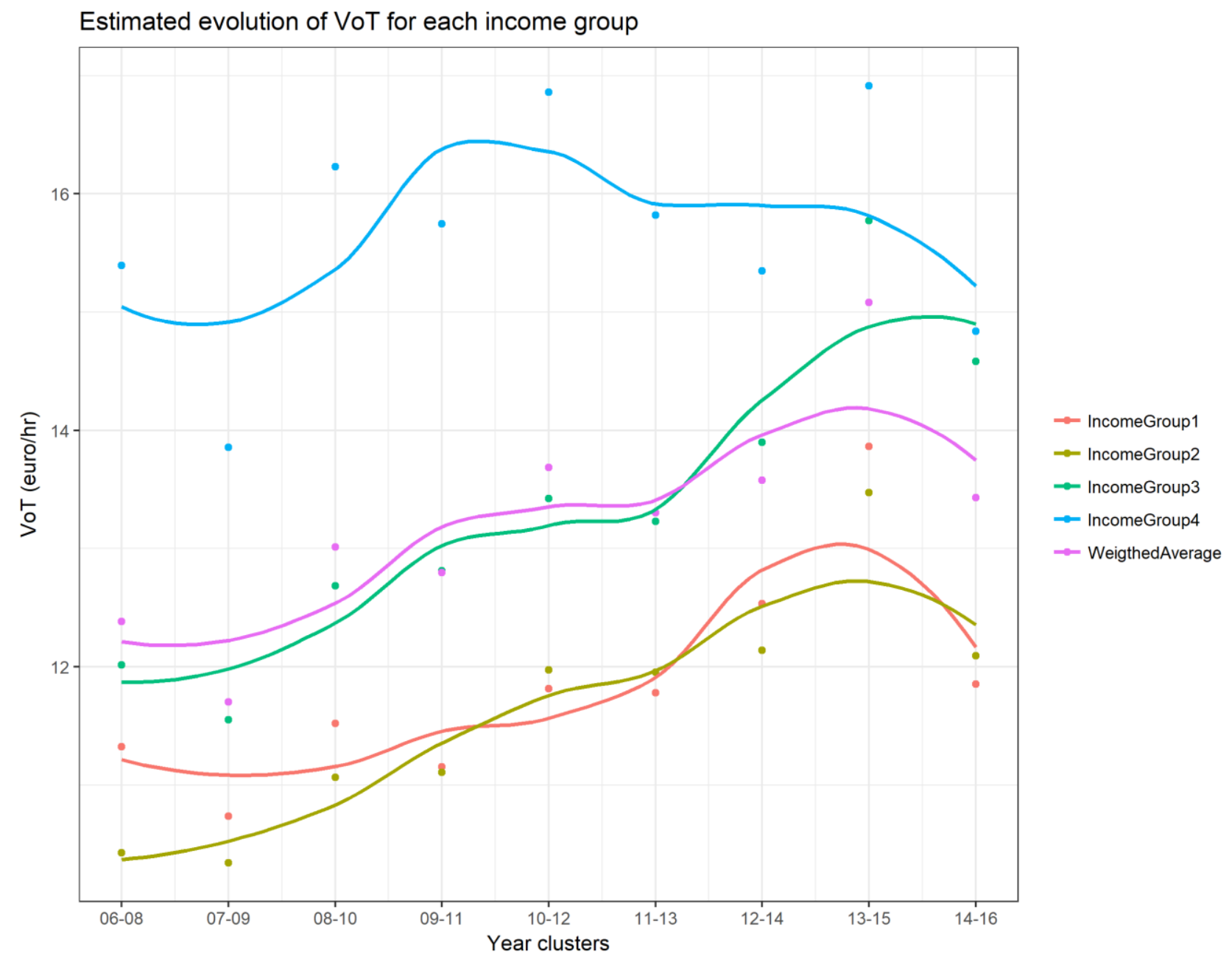

Figure 4: Revealed VTTS across the years 2006-2016.

\begin{tabular}{llllllllll}
$\begin{array}{l}\text { VTTS } \\
\text { Euros/H }\end{array}$ & $\mathbf{0 6 - 0 8}$ & $\mathbf{0 7 - 0 9}$ & $\mathbf{0 8 - 1 0}$ & $\mathbf{0 9 - 1 1}$ & $\mathbf{1 0 - 1 2}$ & $\mathbf{1 1 - 1 3}$ & $\mathbf{1 2 - 1 4}$ & $\mathbf{1 3 - 1 5}$ & $\mathbf{1 4 - 1 6}$ \\
\hline Income Q1 & 11.32 & 10.73 & 11.52 & 11.15 & 11.81 & 11.77 & 12.53 & 13.86 & 11.85 \\
Income Q2 & 10.42 & 10.34 & 11.06 & 11.10 & 11.97 & 11.95 & 12.14 & 13.47 & 12.09 \\
Income Q3 & 12.01 & 11.55 & 12.68 & 12.82 & 13.42 & 13.23 & 13.89 & 15.77 & 14.58 \\
Income Q4 & 15.39 & 13.85 & 16.22 & 15.74 & 16.85 & 15.82 & 15.34 & 16.91 & 14.83 \\
\hline Average & 12.38 & 11.70 & 13.01 & 12.79 & 13.68 & 13.30 & 13.57 & 15.08 & 13.43 \\
\hline
\end{tabular}

Table 4: Average VTTS across income quartiles.

Firstly, the two first income quartiles are relative similar, whereas quartiles 3 and 4 suggest a significantly higher VTTS. This finding is consistent with Börjesson et al. (2012) who find a similar invariance for the $50 \%$ people with lowest incomes. In the newest update of the social VTTS for appraisal (Pilegaard et al. 2006, TRM, 2015b) the average VTTS for 2016 was estimated to 12 Euros/Hour for non-business travel. In the above Table 4, the average value is found to be 13.43 Euros/Hour in 2016. However, as described previously, the latter value is a generic value that includes congestion and waiting time. To facilitate a neutral comparison of the two we have post-calculated the VTTS by extracting only the in-vehicle-travel time (also refer to Figure 2 and Figure 3). This leads to an estimated average VTTS of approximately 12.5 
Euros/Hour, which is almost identical to the recommended VTTS, which was estimated on the basis of SP data.

It is interesting that quartile 3 exhibit the highest homogenous growth over the period. For this group the VTTS increases by more than $20 \%$ for the period as compared to an average growth of slightly above $10 \%$. Interestingly, income quartile 4 exhibits an almost constant VTTS over time but at a higher level. One interpretation of this could be that people with high incomes have newer and more comfortable cars. Another interpretation could be that rich people can afford to live in the city and pay the price of good accessibility. However, it could also suggest that the hypothesis that higher income groups have an inherently different attitude towards money in the sense that they are virtually invariant to cost changes is not correct.

To further test the VTTS variability a bootstrap resampling experiment is performed. It is not straightforward to provide a parametric exact variance estimate for the VTTS as it is expressed as the ratio of two distributions. Bootstrapping on the contrary, can be easily implemented and will provide approximately correct confidence limits provided the model is correct. This is based on the assumption that the parameters for time and cost (by quartiles) are normally distributed with correlation matrix $\Omega_{i}$ and mean vector $\mu_{i}$ for cluster $i$. The normal distribution $N\left(u_{i}, \Omega_{i}\right)$ is revealed from the estimated model and a distribution for the VTTS is revealed by random draws from the joint normal distribution (Canty and Ripley, 2017; Data Flair, 2017). Confidence bands for the simulated values are calculated by finding the appropriate quantiles in a sorted list of VTTS values as shown in Figure 5. 


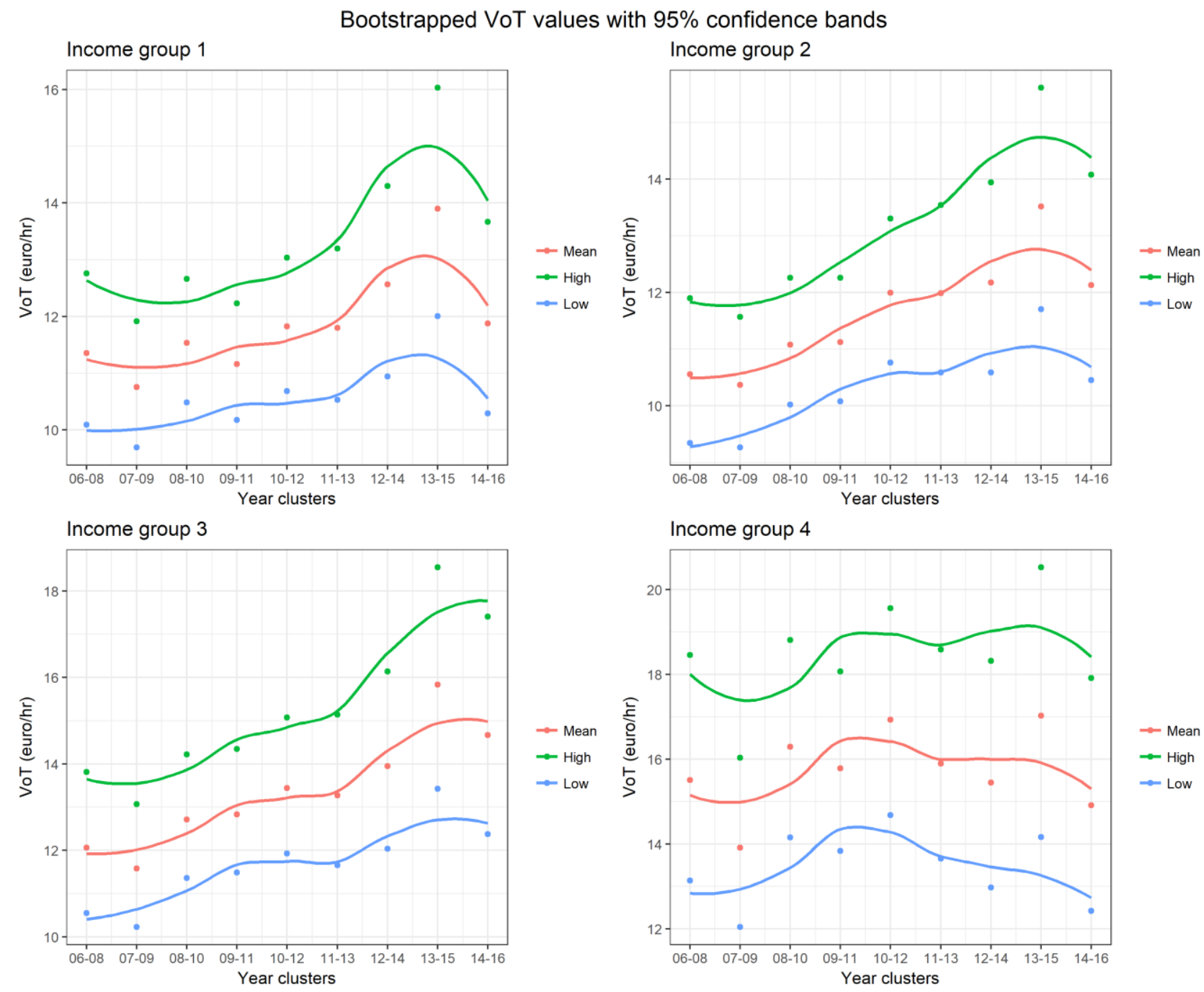

Figure 5: Bootstrapped VTTS for different year clusters and for different income groups with $95 \%$ confidence interval limits.

\subsection{VTTS growth and confounding factors}

In Section 4.2 it was shown that the VTTS increased significantly across the 10 -year period. As discussed in the introduction, there can be many explanations for this. In particular, as we observe numerous structural changes throughout the period, the question is to what extent these structural changes explain the observed trend and to what extent it is the consequence of preference changes or income growth. To investigate this further we consider the following post-regression in (12) where the relative change in VTTS (the left-hand side variable) is regressed onto a set of explanatory variables.

$$
\frac{\operatorname{VTTS}_{n, y}(m)}{\operatorname{VTTS}_{n, y=1}(m)}=\boldsymbol{\vartheta} \boldsymbol{x}_{n, m, y}+\epsilon_{n, m, y}, \forall n, m \in M_{n}, y=1, \ldots, Y
$$

In this regression $\boldsymbol{x}_{n, m, y}$ may include level-of-service variables as well as socio-economic variables and thereby represent a subsequent detailing of the different component. Although there could be many variables our analysis will be limited to two confounding factors only. These two factors are travel distance and travel speed (an instrument for congestion) and are known to be quite strongly positively correlated to 
VTTS (Abrantes and Wardman, 2011; Fosgerau et al., 2007). The variation is embedded in the level-ofservice variables but cannot be identified in the cross-section estimation as the variables are correlated with travel time and travel cost. However, if these variables contribute to the VTTS growth over time we should be able to reveal this from a post-regression analysis. What is interesting is that these factors are the result of long-term structural changes resulting from migration and differences in location patterns.

Clearly, the post-regression operate at the level of individuals and allow us to investigate the effect by level of income. One way of illustrating the results is to illustrate the growth-pattern in VTTS, from equation (12), after having corrected for the change in travel-speed and travel distance. This is illustrated in Figure 6 with the first period acting as reference.

Another way of illustrating the combined effect from these variables is to present the growth in VTTS after the correction. The result is shown in Table 5. It is seen that after adjusting for increasing congestion and increasing travel distance the increase in VTTS decreases from $10 \%$ to $3 \%$ throughout the period. In other words, it is suggested that a main driver of the increased VTTS is that of underlying structural changes.

It should be acknowledged ${ }^{3}$, as also discussed in the introduction, that it is generally difficult to disentangle income effects from structural effects such as distance, speed and congestion. Hence, it is expected that a fair share of the $7 \%$ structural effects is indirectly related to income in one way or the other. However, similar challenges exist for meta studies where VTTS from many studies are regressed on numerous variables of which many are confounding.

\footnotetext{
${ }^{3}$ The authors would like to thank two anonymous reviewers for pointing this out in a clear manner.
} 
Income group 1



Income group 3

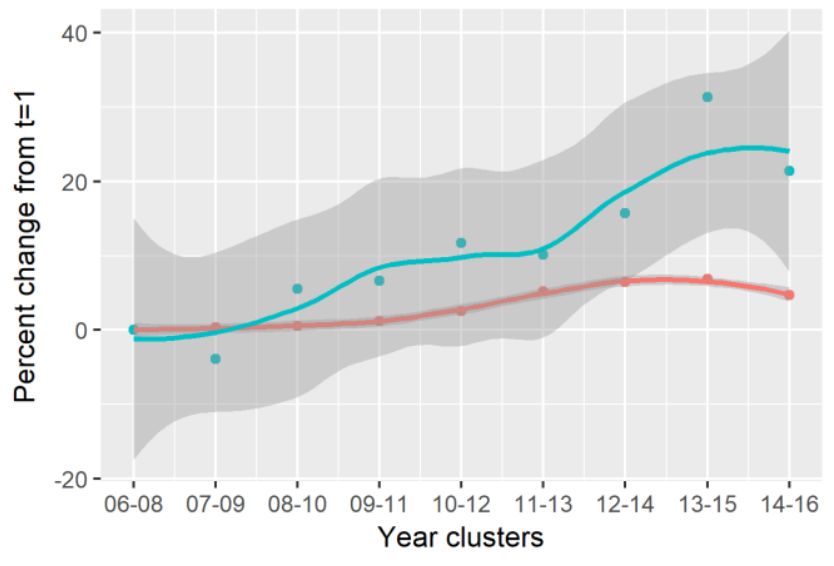

VoT Measure $\because$ Regression expectation of VoT $\because$ Modelled VoT
Income group 2

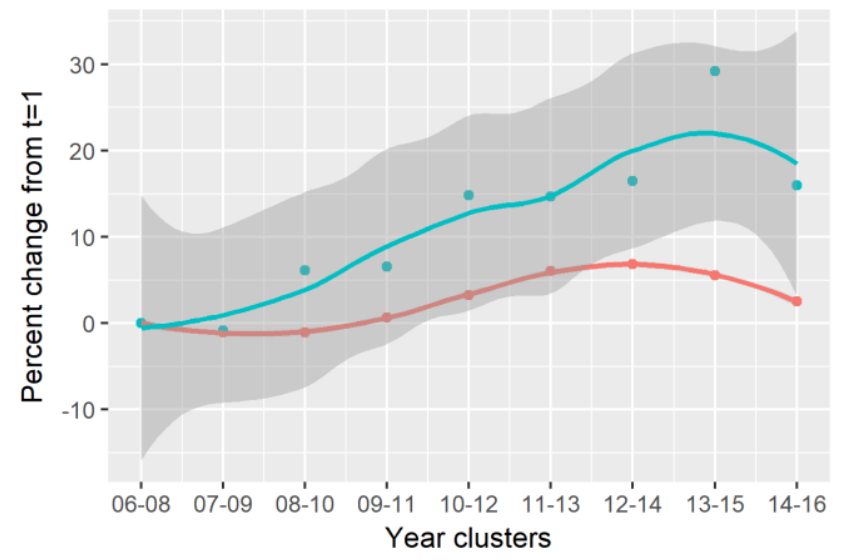

Income group 4



Figure 6: Comparison of modelled VTTS (not filtered for confounding factors) and expected VTTS based on OLS (filtered for travel distance and travel speed).

\begin{tabular}{lccccccccc}
$\begin{array}{l}\text { VTTS } \\
\text { Euros/H }\end{array}$ & $\mathbf{0 6 - 0 8}$ & $\mathbf{0 7 - 0 9}$ & $\mathbf{0 8 - 1 0}$ & $\mathbf{0 9 - 1 1}$ & $\mathbf{1 0 - 1 2}$ & $\mathbf{1 1 - 1 3}$ & $\mathbf{1 2 - 1 4}$ & $\mathbf{1 3 - 1 5}$ & $\mathbf{1 4 - 1 6}$ \\
\hline Group 1 & 11.93 & 11.89 & 11.98 & 12.07 & 12.29 & 12.46 & 12.42 & 12.33 & 12.12 \\
Group 2 & 13.23 & 13.09 & 13.08 & 13.32 & 13.66 & 14.03 & 14.14 & 13.97 & 13.56 \\
Group 3 & 15.07 & 15.13 & 15.16 & 15.26 & $15 . .46$ & 15.86 & 16.04 & 16.11 & 15.78 \\
Group 4 & 18.80 & 18.81 & 18.92 & 19.00 & 19.30 & 19.56 & 19.63 & 19.35 & 19.19 \\
\hline Average & 14.94 & 14.92 & 15.01 & 15.07 & 15.42 & 15.68 & 15.78 & 15.60 & 15.33 \\
\hline
\end{tabular}

Table 5: Average VTTS across income quartiles after filtering for confounding factors.

In Figure 7 we compare the average VTTS with different income measures. It is shown that the average growth in VTTS throughout the period 2006-2016 appears to be closely linked to the growth in the disposable income although there are notable differences for the different years. It is also shown that for the period in question, the relationship between VTTS and GDP (or the GDP per capita) is quite unclear. In the figure the "filtered" VTTS, which represents the growth in VTTS after correcting for increasing travel distance and increasing congestion, is illustrated as well. The filtered VTTS has a much lower growth for the period of approximately $3 \%$ and with a growth pattern that shares similarities with the "unfiltered" VTTS, however less volatile. The filtered VTTS have a growth pattern which is similar to that of the average 
personal gross income. As seen in Figure 7, the cluster 2013-2015 is characterised by a local 'pike' in VTTS. The post-regression presented above suggest that this is related to preferences with respect to travel distance and speed. This is supported by other results as well. Figure A.2 and A.3 in Appendix A indicate that the 'pike' is persistent across different modes and purposes. Figure B.1 and B.2 Appendix B suggest it has nothing to do with speed and cost profiles. Also, it is persistent across income segments as shown in Figure 5. When looking at the parameter-estimates (Table D.1 in Appendix D) it is clear that the timeparameter 'peaks' in segment 13-15 while at the same time cost-parameters are average. Therefor the conclusion is that this is most likely the effect of level-of-service fluctuations (Figure 2 and Figure 3 ) in combination with sample noise inherited in the data.



Figure 7: Inter-temporal changes in VTTS compared to different measures of income.

The general deduction from Figure 7 can be summarised in a few statements. Firstly, there is a clear effect of the financial crisis on the VTTS in the darkest years of 2007-2009. Secondly, although many income-toVTTS relationships are spurious and volatile, increasing income has without questions, a positive effect on 
VTTS over the period. Depending on the measure of income and the form of the VTTS, the elasticity, is between 0.3 and 1.0. However, as part of the "structural effects" related to distance and congestion is likely to be driven by income, it is expected that the average elasticity is higher than 0.3.

The study also find clear and significant cross-sectional income-to-VTTS elasticities (refer to Appendix D), although these are lower than the inter-temporal elasticities. One reason is that in the estimation we considers gross incomes rather than after-tax incomes. As the Danish tax system is progressive, it means that the curves would be somewhat steeper if measured according to an after-tax income. Moreover, in the estimation we adjust for a number of time dummies linked with the residential area and the car-ownership and to the extent these effects are indirectly linked with income (and VTTS) it may capture some of the variation.

\section{Conclusion and summary}

The paper presents a pooled cross-section analysis of VTTS over the period from 2006 to 2016. The period is characterised by variation in income (due to the years of financial crisis), variation in fuel prices due to the "third" oil crisis, structural changes (urbanisation and labour market specialisation), increasing congestion due to increased urbanisation and finally, the phasing-in of mobile information technologies which have evolved from a negligible market share to an almost full 4G coverage in 2016.

By utilising the rich variation in the underlying data the paper sets out to explore several fundamental hypotheses of interest for the appraisal community as well as for the transport modelling community. The main conclusions offered in the paper are as follows;

- It is shown that the financial crisis did have a negative temporary effect on VTTS.

- It is strongly indicated that there is no sign of a declining VTTS for the period as a whole although in recent years there is a declining tendency.

- It is suggested that a significant driver of increasing VTTS is that of increased congestion and travel distances. It goes without saying that income effects may itself be a driver of these variables.

- Increasing income is without any doubt positively correlated with VTTS and the elasticity lies somewhere between 0.3 and 1 , but presumably closer to 1 than to 0.3 .

It is also shown that there are differences in how the inter-temporal and intra-temporal VTTS relate to income. Our estimates suggest that cross-section elasticities are smaller than inter-temporal elasticities as confirmed in other studies.

These conclusions lead to three main recommendations for future VTTS studies. Firstly, it underlines the fact that the VTTS is a moving target throughout time and measures preferences only for the current population and varies with the context in which people are measured. Secondly, it challenges the idea that mobile broadband, better cars and more comfort will automatically lead to a decline in VTTS. These factors seem to be, at least temporally outweighed, by structurally conditioned factors and could suggest that the future, with autonomous cars and better online communication, may not lead to a significant decline in VTTS as expected by many. Thirdly, with respect to the inter-temporal link between income and VTTS the results are not unambiguous. On the one hand we show that the filtered VTTS increases more than the real GDP per capita, however, at the same time it increases significantly less than the disposable income. As 
structural effects may partly be explained by indirect income effects, it may be concluded that the study supports the assumption of a positive income-to-VTTS elasticity. 


\section{References}

Abegaz, D.F., Hjorth, K., Rich, J. (2017) Testing the slope model of scheduling preferences on stated preference data. Transportation Part B. http://dx.doi.org/10.1016/j.trb.2017.08.001

Abrantes, P.A.L., Wardman M.R. (2011) Meta-analysis of UK values of travel time: An update.

Transportation Research Part A: Policy and Practice Vol 45(1) pp 1-17.

Bates, J. (1994) Reflections on Stated Preference Theory and Practice reprinted. Travel Behaviour Research: Updating the State of Play, eds. Ortuzar, J., Hensher, D and Jara-Diaz, S., 1998, Elsevier.

Börjesson, M., Fosgerau, M., Algersa, S. (2012) On the income elasticity of the value of travel time.

Transportation Research Part A, Vol. 46(2), 368-377.

Ben-Akiva and Lerman (1985) Discrete Choice Analysis: Theory and Application to Travel Demand. MIT Press, Cambridge.

Canty A., Ripley, B. (2017) Package 'boot'. CRAN repository.

Url: https://cran.r-project.org/web/packages/boot/boot.pdf

Christensen, H., Skougaard, B.Z. (2015) Documentation of the Danish National Travel Survey. Report DTU Transport.

Url: $\underline{\text { http://www.modelcenter.transport.dtu.dk/transportvaneundersoegelsen/dokumentation }}$

Daly, A. (2010) Cost damping in travel demand models. Technical report, Rand Europe.

Url: http://www.rand.org/pubs/technical reports/TR717.html

Daly, A., Carrasco, J. (2009) The influence of trip length on marginal time and money values. The Expanding Sphere of Travel Behaviour Research: Selected papers from the proceedings of the $11^{\text {th }}$ Conference on Travel Behaviour Research, eds. Kitamura, R., Emerald Books.

Data Flair (2018) Bootstrapping in R - Bootstrap Resampling and Examples.

Url: https://data-flair.training/blogs/bootstrapping-in-r/

Deloitte (2015) Transport in the Digital Age Disruptive Trends for Smart Mobility.

Url: https://www2.deloitte.com/content/dam/Deloitte/uk/Documents/bps/deloitte-uk-transport-digitalage.pdf

Douglas N. J., Wallis I. P. (2013) Predicting the Value of Public Transport In-Vehicle Time, Australasian Transport Research Forum 2013 Proceedings.

Url: http://atrf.info/papers/2013/2013 douglas wallis.pdf

Elhorst, J.P., Oosterhaven, J. (2008) Integral cost-benefit analysis of Maglev projects under market imperfections. Journal of Transport and Land Use 1:1, pp. 65-87 
Fosgerau, M. (2005) Unit income elasticity of the value of travel time savings. 8th NECTAR Conference, Las Palmas GC June, 2005

Fosgerau, M., Hjorth, K., Vincent L.-J., S. (2007) The Danish Value of Time Study. Final Report 5. Danish Transport Research Institute. ISSN: 1601-9458.

Gaudry, M., Jara-Diaz, S., Ortuzar, J. de D. (1989) Value of time sensitivity to model specification, Transportation Research B 23(2), pp. 151-158.

Gunn, H. (1983) "Generalised Cost" or "Generalised Time". A note on the forecasting implications. Journal of Transport Economics and Policy XVII, pp. 91-94.

Gunn, H.F. (2001) Spatial and temporal transferability of relationships between travel demand, trip cost and travel time. Transportation Research Part E, 37 (2/3) (2001), pp. 163-169

Heatco (2006) Developing Harmonised European Approaches for Transport Costing and Project Assessment, HEATCO Deliverable 5,

Url: http://heatco.ier.uni-stuttgart.de/

Hensher, David A. (2011) Valuation of travel time savings. A Handbook of Transport Economics eds. A. de Palma, R. Lindsey, E. Quinet, and R. Vickerman, pp. 135-159, Edward Elgar.

Jara-Diaz, S. (2007) Transport Economic Theory, Emerald Group Publishing Limit.

Jara-Diaz, S. (2002) The Goods/Activities Framework for Discrete Travel Choices: Indirect Utility and Value of Time. In Perpetual Motion: Travel Behavior Research Opportunities and Application Challenges eds. Mahmassani, H. pp. 415-430, Pergamon.

Knudsen, M.Aa., Rich J. (2013) Ex post study of the passenger consumer benefits of the Oresund Bridge, Transport Policy, 27, 53-65.

King, J. (2014) How Transportation Technologies Will Change Everything. GT Magazine Transportation.

Url: http://www.govtech.com/transportation/How-Transportation-Technologies-Will-Change-Everything$\underline{. h \mathrm{tml}}$

Mackie, P.J., Wardman, M., Fowkes, A.S., Whelan, G.A., Nellthorp, J., Bates, J. (2003) Value of Travel Time Savings in the UK. Report to the Department for Transport.

Pilegaard, N., Fosgerau, M., Jensen, M.P., Lyk-Jensen, S. (2006) TERESA (Transport- og Energimini-steriets Regnearksmodel til Sam-fundsøkonomisk Analyse) for transportprojekter, Notat 32006.

Url: http://www.modelcenter.transport.dtu.dk/Lmedia/Centre/Modelcenter/modeller\%20og\%20publikationer/TERESA-dokumentation-2006.ashx

Rich, J. and Hansen, C.O. (2016) The Danish National Passenger Model - Model specification and results. European Journal of Transport and Infrastructure Research, 16(4): 573-599. 
Rich, J., Mabit, S. (2015) Cost damping and functional form in transport models, Transportation, 43:889:912.

Quinet E. (2014) L'évaluation des investissements publics Futuribles 2014, no. 401.

Url: https://www.futuribles.com/fr/revue/401/levaluation-des-investissements-publics/

Shires, J.D., de Jong, G.C. (2009) An international meta-analysis of values of travel time savings. Evaluation and Program Planning 32: 315-325.

Small, K. (2012) Valuation of Travel Time, Economics of Transportation, 1(1), 2012.

DOI: 10.1016/j.ecotra.2012.09.002.

Url: https://www.socsci.uci.edu/ ksmall/VTTS\%20review.pdf

Small, K., Nolan, R., Chu, X., Lewis, D. (1999) Valuation of Travel-Time Savings and Predictability in Congested Conditions for Highway User-Cost Estimation. NCHRP Report 431. Transport Research Board, National Research Council.

TRM (2015a) Opdatering af TERESA version 4.0 Dokumentationsnotat.

Url: http://www.modelcenter.transport.dtu.dk//media/Centre/Modelcenter/modeller\%20og\%20publikationer/DokumentationsnotatTERESA 4.ashx

TRM (2015b) Manual for samfunds økonomisk analyse på transportområdet - Anvendt metode of praksis i Transportministeriet. ISBN: 978-97-93292-05-5.

Url: https://www.trm.dk/da/publikationer/2015/manual-for-samfundsoekonomisk-analyse-paa$\underline{\text { transportomraadet }}$

Zheng, L., Hensher, D.A., Ho, C. (2018) An empirical investigation of values of travel time savings from stated preference data and revealed preference data, Transportation Letters, DOI:

10.1080/19427867.2018.1546806

Wardman, M.R. (2004) Public transport values of time. Transport Policy, 11 (4). pp. 363-377. ISSN 0967070X

Webtag (2014) Values of Time and Vehicle Operating Costs, TAG Unit 3.5.6, Department for Transport. Url:

http://webarchive.nationalarchives.gov.uk/20140304110038/http://www.dft.gov.uk/webtag/documents/e xpert/pdf/U3 5 6-Jan-2014.pdf

Woodridge, J. M. (2002) Econometric Analysis of Cross Section and Panel Data. MIT Press, Cambridge Massachusetts London England.

Url: https://jrvargas.files.wordpress.com/2011/01/wooldridge j2002 econometric analysis of cross section and panel data.pdf 
Appendix A: VTTS by distance, mode and trip purpose

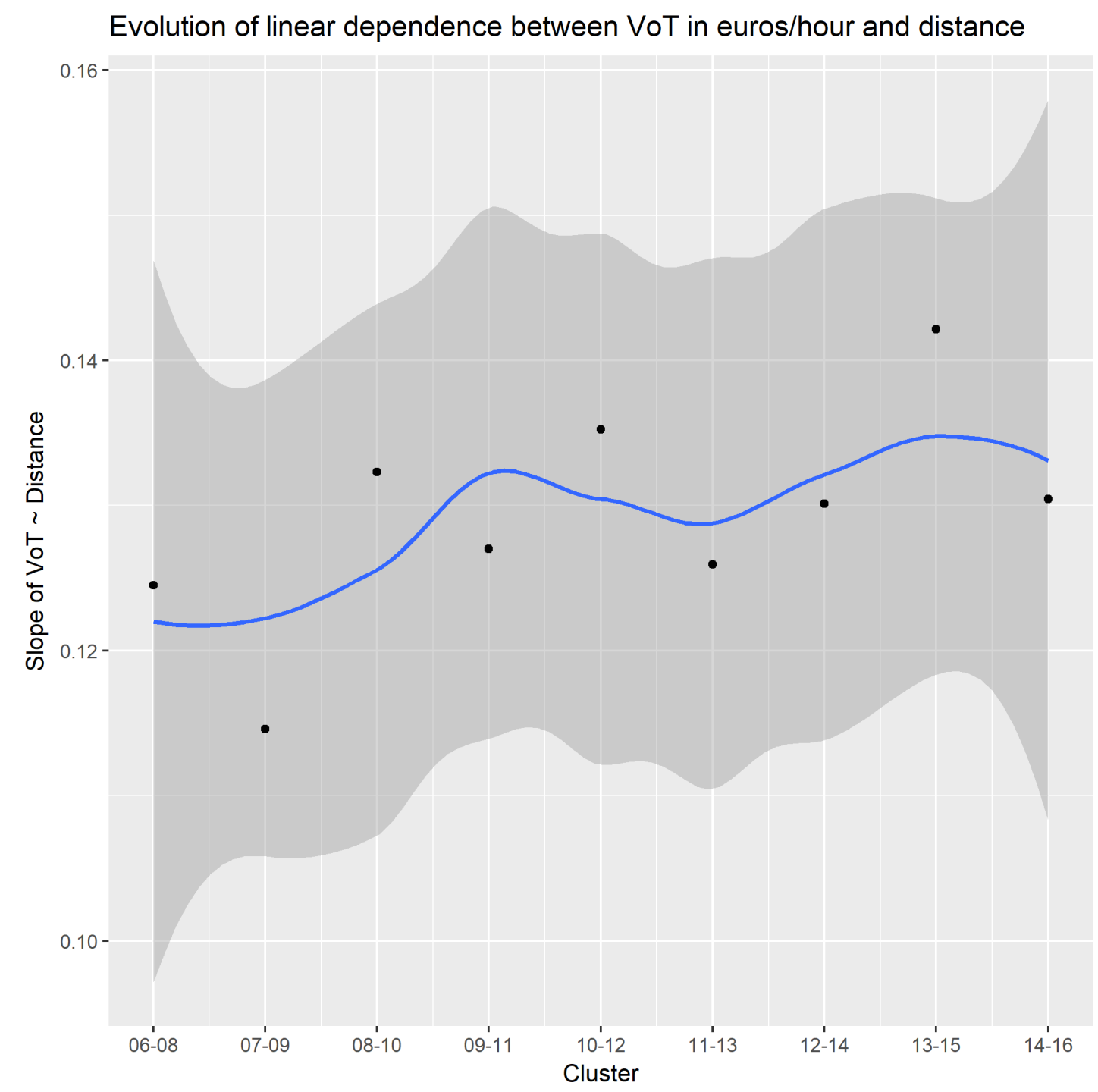

Figure A.1: Elasticity of VTTS to distance over time. 


\section{Quantile evolution for different transport modes}

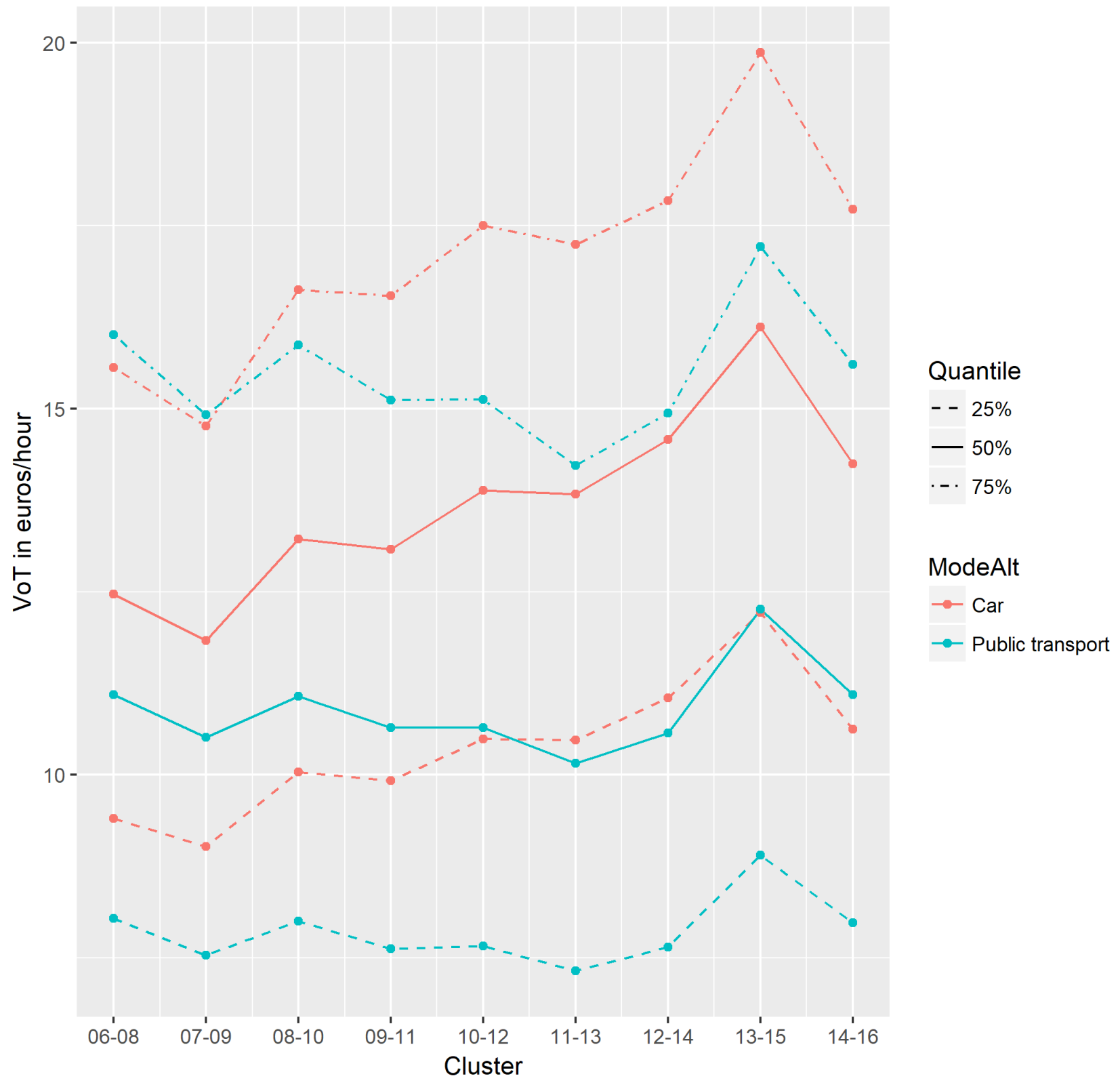

Figure A.2: VTTS by mode over time. 
Quantile evolution for purposes of trip



Figure A.3: VTTS by purpose over time. 


\section{Appendix B: Marginal cost and speed over time}

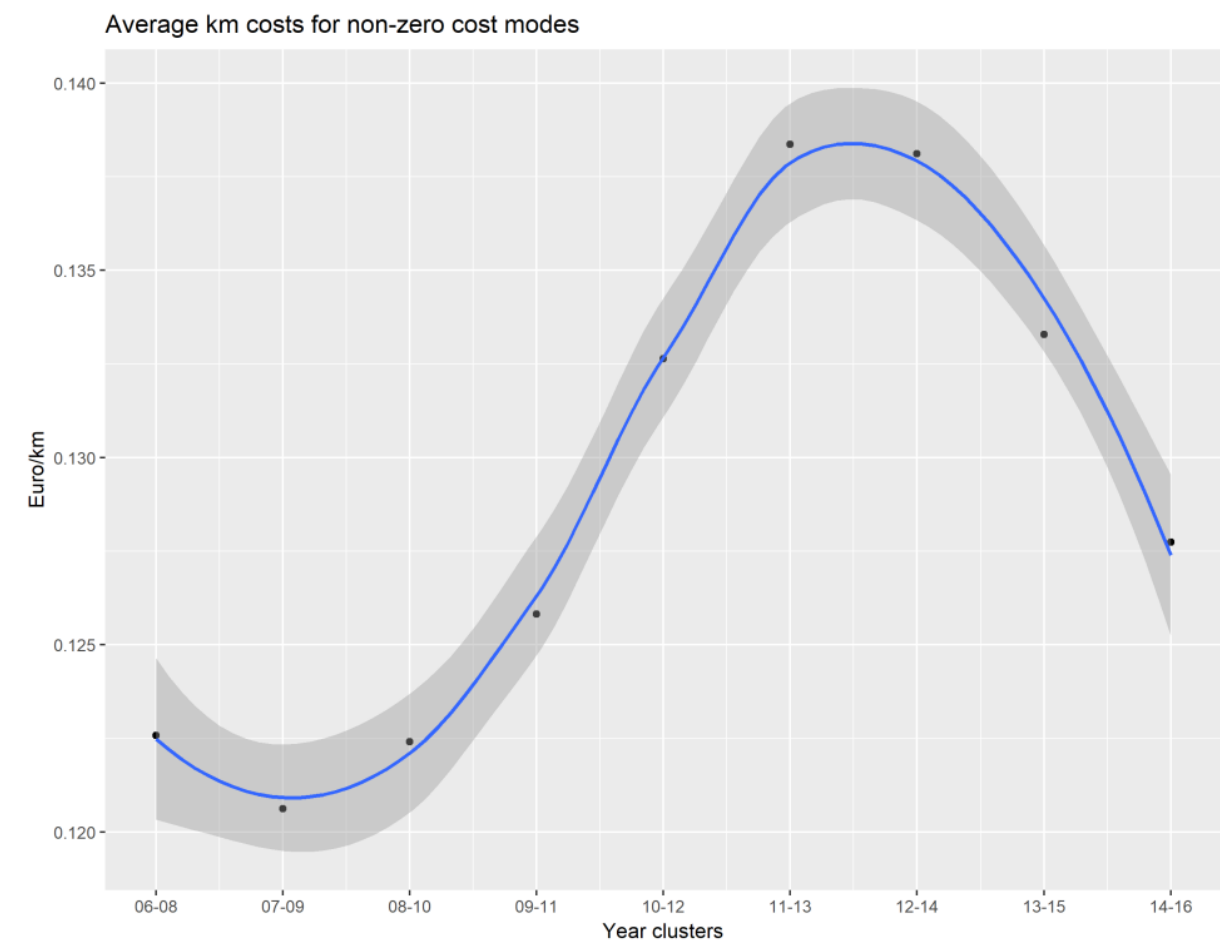

Figure B.1: Average cost per $\mathrm{km}$ for modes which have an associated cost

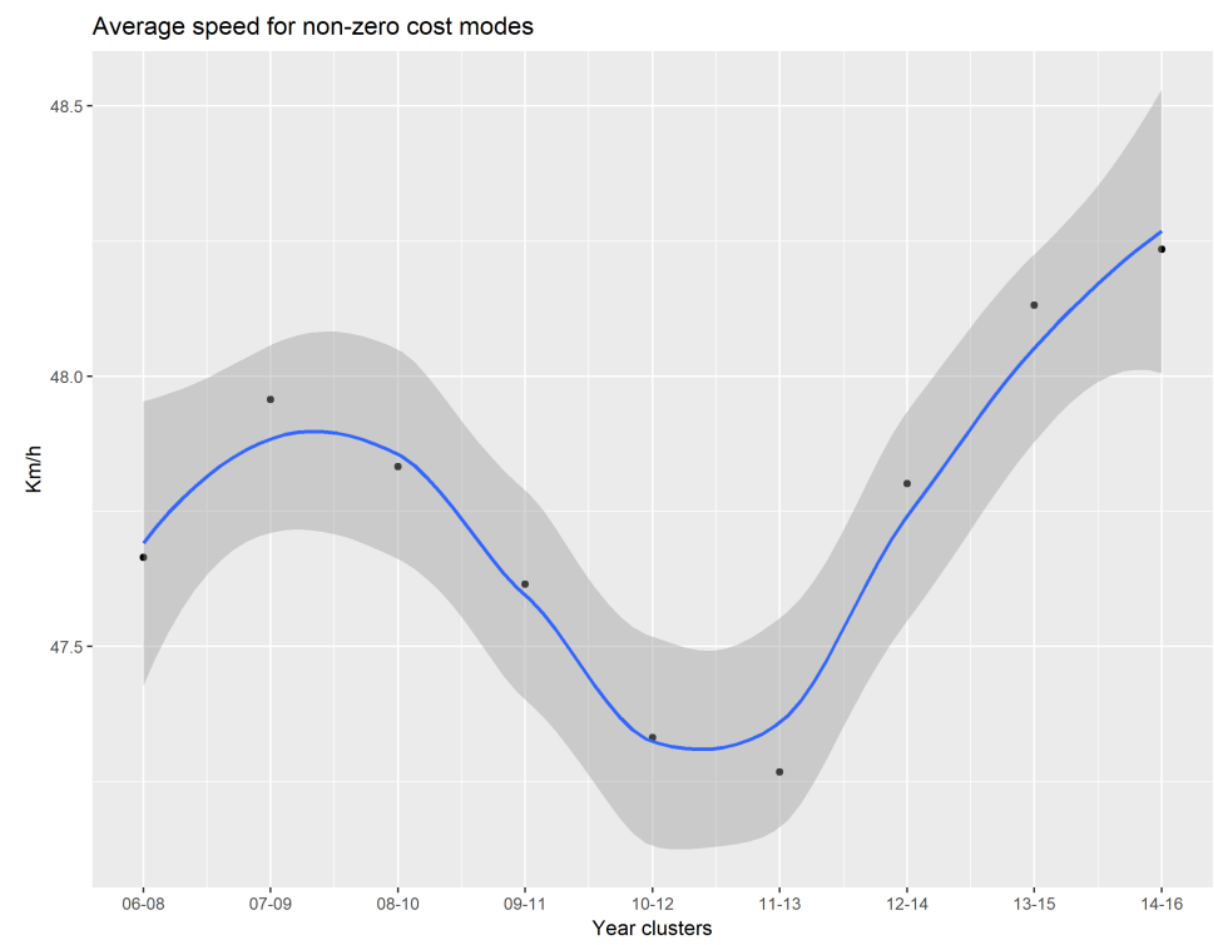

Figure B.2: Average speed for modes which have an associated cost 
Appendix C: Goodness-of-fit heat-map

\begin{tabular}{|l|lllllllll|}
\hline Lambda & $06-08$ & $07-09$ & $08-10$ & $09-10$ & $10-12$ & $11-13$ & $12-14$ & $13-15$ & $14-16$ \\
\hline 0 & 314 & $\mathbf{5 0 5}$ & $\mathbf{5 1 0}$ & $\mathbf{5 4 0}$ & $\mathbf{4 0 2}$ & $\mathbf{2 9 2}$ & $\mathbf{2 1 1}$ & 122 & 101 \\
0.1 & $\mathbf{3 2 1}$ & 464 & 463 & 483 & 377 & 276 & 201 & $\mathbf{1 4 0}$ & $\mathbf{1 1 2}$ \\
0.2 & 241 & 337 & 333 & 349 & 278 & 204 & 145 & 107 & 86 \\
0.3 & 175 & 239 & 234 & 245 & 199 & 146 & 103 & 78 & 62 \\
0.4 & 125 & 167 & 162 & 170 & 140 & 102 & 72 & 55 & 44 \\
0.5 & 87 & 114 & 109 & 115 & 96 & 71 & 49 & 38 & 31 \\
0.6 & 58 & 74 & 71 & 74 & 62 & 46 & 32 & 25 & 20 \\
0.7 & 34 & 43 & 41 & 43 & 37 & 27 & 19 & 15 & 12 \\
0.8 & 16 & 19 & 18 & 19 & 16 & 12 & 9 & 7 & 6 \\
0.9 & 0 & 0 & 0 & 0 & 0 & 0 & 0 & 0 & 0 \\
\hline
\end{tabular}

Figure C.1: Goodness-of-fit heat map measured as positive Log-Likelihood gain when compared to the reference case of pure log-linear functions. Lambda $=0$ constitute the logarithmic case

Prior to the heat map all combinations of $\gamma$ for both time and cost were estimated. This was then combined into a 2-dimensional (Figure C.1) heat map as the patterns for cost and time were quite similar. The map illustrates that of the possible damping combinations for cost and time, the specification with pure logarithmic forms for both time and cost was the best one overall.

\section{Appendix D: Model parameters}

\begin{tabular}{|c|c|c|c|c|c|c|c|c|c|}
\hline Parameter & $06-08$ & 07-09 & $08-10$ & $09-11$ & $10-12$ & $11-13$ & $12-14$ & $13-15$ & $14-16$ \\
\hline Log travel time & $\begin{array}{l}-0.9396 \\
(0.0325)\end{array}$ & $\begin{array}{l}-0.9111 \\
(0.0278)\end{array}$ & $\begin{array}{l}-0.9426 \\
(0.0272)\end{array}$ & $\begin{array}{l}-0.9169 \\
(0.0261)\end{array}$ & $\begin{array}{l}-0.9369 \\
(0.0292)\end{array}$ & $\begin{array}{l}-0.9444 \\
(0.0338)\end{array}$ & $\begin{array}{l}-1.0133 \\
(0.0421)\end{array}$ & $\begin{array}{l}-1.0798 \\
(0.0444)\end{array}$ & $\begin{array}{l}-0.9969 \\
(0.0427)\end{array}$ \\
\hline $\begin{array}{l}\text { Travel time } \\
\text { (walk/bike) }\end{array}$ & $\begin{array}{l}-0.1157 \\
(0.0017)\end{array}$ & $\begin{array}{l}-0.1113 \\
(0.0013)\end{array}$ & $\begin{array}{l}-0.1142 \\
(0.0013)\end{array}$ & $\begin{array}{l}-0.1121 \\
(0.0011)\end{array}$ & $\begin{array}{l}-0.1149 \\
(0.0013)\end{array}$ & $\begin{array}{l}-0.1143 \\
(0.0015)\end{array}$ & $\begin{array}{l}-0.1182 \\
(0.0020)\end{array}$ & $\begin{array}{l}-0.1189 \\
(0.0022)\end{array}$ & $\begin{array}{l}-0.1155 \\
(0.0020)\end{array}$ \\
\hline $\begin{array}{l}\text { Log cost } \\
\text { (quartile 1) }\end{array}$ & $\begin{array}{l}-0.4604) \\
(0.0186)\end{array}$ & $\begin{array}{l}-0.4720 \\
(0.0163)\end{array}$ & $\begin{array}{l}-0.4572 \\
(0.0151)\end{array}$ & $\begin{array}{l}-0.4697 \\
(0.0143)\end{array}$ & $\begin{array}{l}-0.4783 \\
(0.0156)\end{array}$ & $\begin{array}{l}-0.4969 \\
(0.0185)\end{array}$ & $\begin{array}{l}-0.4836 \\
(0.0221)\end{array}$ & $\begin{array}{l}-0.4353 \\
(0.0230)\end{array}$ & $\begin{array}{l}-0.4543 \\
(0.0225)\end{array}$ \\
\hline $\begin{array}{l}\text { Log cost } \\
\text { (quartile 2) }\end{array}$ & $\begin{array}{l}-0.4280 \\
(0.0192)\end{array}$ & $\begin{array}{l}-0.4205 \\
(0.0169)\end{array}$ & $\begin{array}{l}-0.4093 \\
(0.0155)\end{array}$ & $\begin{array}{l}-0.4090 \\
(0.0145)\end{array}$ & $\begin{array}{l}-0.4177 \\
(0.0156)\end{array}$ & $\begin{array}{l}-0.4352 \\
(0.0190)\end{array}$ & $\begin{array}{l}-0.4515 \\
(0.0229)\end{array}$ & $\begin{array}{l}-0.4195 \\
(0.0233)\end{array}$ & $\begin{array}{l}-0.4142 \\
(0.0226)\end{array}$ \\
\hline $\begin{array}{l}\text { Log cost } \\
\text { (quartile 3) }\end{array}$ & $\begin{array}{l}-0.3754 \\
(0.020)\end{array}$ & $\begin{array}{l}-0.3726 \\
(0.0175)\end{array}$ & $\begin{array}{l}-0.3560^{\prime} \\
(0.0161)\end{array}$ & $\begin{array}{l}-0.3548 \\
(0.0152)\end{array}$ & $\begin{array}{l}-0.3717 \\
(0.0163)\end{array}$ & $\begin{array}{l}-0.3981 \\
(0.0193)\end{array}$ & $\begin{array}{l}-0.4147 \\
(0.0231)\end{array}$ & $\begin{array}{l}-0.3778 \\
(0.0243)\end{array}$ & $\begin{array}{l}-0.3559 \\
(0.0239)\end{array}$ \\
\hline $\begin{array}{l}\text { Log cost } \\
\text { (quartile 4) }\end{array}$ & $\begin{array}{l}-0.2865 \\
(0.0210)\end{array}$ & $\begin{array}{l}-0.3059 \\
(0.0184)\end{array}$ & $\begin{array}{l}-0.2752 \\
(0.0168)\end{array}$ & $\begin{array}{l}-0.2843 \\
(0.0161)\end{array}$ & $\begin{array}{l}-0.2922 \\
(0.0173)\end{array}$ & $\begin{array}{l}-0.3790 \\
(0.0208)\end{array}$ & $\begin{array}{l}-0.3581 \\
(0.0249)\end{array}$ & $\begin{array}{l}-0.3298 \\
(0.0262)\end{array}$ & $\begin{array}{l}-0.3305 \\
(0.0251)\end{array}$ \\
\hline $\begin{array}{l}\text { Region Dum } \\
\text { Walk } 1\end{array}$ & $\begin{array}{l}2.6513 \\
(0.1196)\end{array}$ & $\begin{array}{l}2.6403 \\
(0.1049)\end{array}$ & $\begin{array}{l}3.0552 \\
(0.1011)\end{array}$ & $\begin{array}{l}3.1569 \\
(0.0978)\end{array}$ & $\begin{array}{l}3.2047 \\
(0.1063)\end{array}$ & $\begin{array}{l}2.9953 \\
(0.1278)\end{array}$ & $\begin{array}{l}3.0535 \\
(0.1491)\end{array}$ & $\begin{array}{l}3.0225 \\
(0.1517)\end{array}$ & $\begin{array}{l}2.9792 \\
(0.1437)\end{array}$ \\
\hline $\begin{array}{l}\text { Region Dum } \\
\text { Walk } 2\end{array}$ & $\begin{array}{l}1.9277 \\
(0.0897)\end{array}$ & $\begin{array}{l}1.9397 \\
(0.0805)\end{array}$ & $\begin{array}{l}2.2884 \\
(0.0792)\end{array}$ & $\begin{array}{l}2.3838 \\
(0.0785)\end{array}$ & $\begin{array}{l}2.4485 \\
(0.086)\end{array}$ & $\begin{array}{l}2.3032 \\
(0.1048)\end{array}$ & $\begin{array}{l}2.4113 \\
(0.1242)\end{array}$ & $\begin{array}{l}2.4028 \\
(0.1292)\end{array}$ & $\begin{array}{l}2.4340 \\
(0.1232)\end{array}$ \\
\hline Region Dum & 2.1875 & 2.1925 & 2.4043 & 2.5436 & 2.5378 & 2.3776 & 2.3348 & 2.3683 & 2.6793 \\
\hline Walk 3 & (0.0989) & (0.088) & $(0.0852)$ & $(0.0843)$ & (0.0923) & (0.1131) & (0.1335) & (0.138) & (0.133) \\
\hline Region Dum & 2.0949 & 2.0552 & 2.4034 & 2.5124 & 2.5961 & 2.4145 & 2.6306 & 2.5071 & 2.6455 \\
\hline Walk 4 & $(0.1188)$ & $(0.1045)$ & $(0.0981)$ & $(0.0957)$ & $(0.1061)$ & $(0.1315)$ & $(0.1633)$ & $(0.1651)$ & (0.1578) \\
\hline Region Dum & 1.7108 & 1.7859 & 2.0875 & 2.2413 & 2.2791 & 2.0804 & 1.9279 & 2.2258 & 2.4545 \\
\hline Walk 5 & $(0.1432)$ & (0.1269) & $(0.117)$ & $(0.1128)$ & $(0.1215)$ & $(0.1458)$ & (0.1777) & (0.1905) & (0.1918) \\
\hline Region Dum & 2.1556 & 2.1628 & 2.4412 & 2.5404 & 2.5468 & 2.4096 & 2.506 & 2.603 & 2.6948 \\
\hline Walk 6 & $(0.0834)$ & $(0.0748)$ & $(0.0744)$ & $(0.0743)$ & $(0.0815)$ & (0.0999) & $(0.1182)$ & $(0.1232)$ & (0.1177) \\
\hline Region Dum & 2.2749 & 2.1319 & 2.2843 & 2.4253 & 2.5092 & 2.4084 & 2.481 & 2.6908 & 2.8343 \\
\hline Walk 7 & $(0.1217)$ & (0.1058) & $(0.1004)$ & $(0.0981)$ & $(0.1078)$ & $(0.1303)$ & $(0.1541)$ & $(0.1657)$ & (0.1605) \\
\hline $\begin{array}{l}\text { Region Dum. } \\
\text { Bike } 1\end{array}$ & $\begin{array}{l}1.733 \\
(0.1184)\end{array}$ & $\begin{array}{l}1.7954 \\
(0.1039)\end{array}$ & $\begin{array}{l}2.0844 \\
(0.101)\end{array}$ & $\begin{array}{l}2.1591 \\
(0.0978)\end{array}$ & $\begin{array}{l}2.1336 \\
(0.1067)\end{array}$ & $\begin{array}{l}1.9924 \\
(0.1277)\end{array}$ & $\begin{array}{l}2.0951 \\
(0.1499)\end{array}$ & $\begin{array}{l}2.1327 \\
(0.1531)\end{array}$ & $\begin{array}{l}2.0872 \\
(0.1457)\end{array}$ \\
\hline Region Dum. & 0.643 & 0.664 & 0.8839 & 0.9577 & 0.9715 & 0.8725 & 0.9069 & 0.8881 & 0.8616 \\
\hline
\end{tabular}




\begin{tabular}{|c|c|c|c|c|c|c|c|c|c|}
\hline Bike 2 & $(0.0915)$ & $(0.0821)$ & $(0.0811)$ & $(0.0804)$ & $(0.0883)$ & $(0.1071)$ & (0.1269) & $(0.1324)$ & (0.1268) \\
\hline Region Dum. & 0.5983 & 0.5973 & 0.6941 & 0.7685 & 0.7208 & 0.5747 & 0.5245 & 0.4994 & 0.7391 \\
\hline Bike 3 & $(0.1017)$ & $(0.091)$ & $(0.0882)$ & $(0.0877)$ & $(0.0961)$ & $(0.1176)$ & $(0.1386)$ & $(0.1446)$ & (0.1404) \\
\hline Region Dum. & 0.6442 & 0.5522 & 0.669 & 0.713 & 0.6979 & 0.6564 & 0.706 & 0.4482 & 0.3321 \\
\hline Bike 4 & $(0.1192)$ & (0.1059) & $(0.1006)$ & $(0.0987)$ & $(0.1103)$ & $(0.1351)$ & (0.169) & $(0.1737)$ & (0.1726) \\
\hline Region Dum. & 0.9083 & 1.0024 & 1.1291 & 1.2418 & 1.2704 & 1.0838 & 1.1093 & 1.1759 & 1.4002 \\
\hline Bike 5 & $(0.1341)$ & (0.1191) & $(0.1118)$ & $(0.1085)$ & (0.1171) & $(0.1402)$ & $(0.1665)$ & $(0.1813)$ & (0.1845) \\
\hline Region Dum. & 0.5377 & 0.5562 & 0.7313 & 0.8106 & 0.778 & 0.6377 & 0.6302 & 0.6826 & 0.7621 \\
\hline Bike 6 & $(0.0855)$ & $(0.0767)$ & $(0.0765)$ & $(0.0764)$ & $(0.0839)$ & $(0.1024)$ & $(0.121)$ & $(0.1269)$ & (0.1219) \\
\hline Region Dum. & 0.7748 & 0.694 & 0.7804 & 0.854 & 0.9184 & 0.8403 & 0.968 & 1.2261 & 1.3368 \\
\hline Bike 7 & (0.1231) & $(0.1071)$ & $(0.1016)$ & $(0.0996)$ & (0.109) & $(0.1317)$ & (0.1549) & $(0.1668)$ & (0.1621) \\
\hline Region Dum. Car & 0.8342 & 0.7817 & 0.9015 & 0.9304 & 0.9385 & 0.8137 & 0.9943 & 0.9668 & 0.892 \\
\hline Driver 1 & (0.119) & $(0.1046)$ & $(0.1019)$ & $(0.0994)$ & (0.109) & $(0.1314)$ & $(0.1537)$ & $(0.1565)$ & $(0.1466)$ \\
\hline Region Dum. Car & 0.4675 & 0.4165 & 0.4716 & 0.4725 & 0.5049 & 0.3863 & 0.4223 & 0.3793 & 0.4608 \\
\hline Driver 2 & $(0.0835)$ & $(0.0761)$ & (0.0766) & (0.0769) & $(0.0851)$ & (0.1047) & $(0.1242)$ & $(0.1281)$ & (0.1204) \\
\hline Region Dum. Car & 0.4926 & 0.4187 & 0.3888 & 0.4194 & 0.3904 & 0.3471 & 0.3014 & 0.3269 & 0.5154 \\
\hline Driver 3 & (0.089) & $(0.0803)$ & $(0.0796)$ & (0.0799) & $(0.0882)$ & (0.109) & (0.129) & $(0.133)$ & (0.1275) \\
\hline Region Dum. Car & 0.372 & 0.2768 & 0.2649 & 0.2968 & 0.3636 & 0.336 & 0.5164 & 0.3888 & 0.3974 \\
\hline Driver 4 & $(0.1031)$ & $(0.0915)$ & $(0.0889)$ & $(0.088)$ & $(0.0983)$ & $(0.122)$ & $(0.1516)$ & (0.153) & $(0.1456)$ \\
\hline Region Dum. Car & 0.3073 & 0.3826 & 0.3851 & 0.3614 & 0.3453 & 0.3011 & 0.3212 & 0.3929 & 0.5968 \\
\hline Driver 5 & $(0.1282)$ & $(0.1146)$ & $(0.1085)$ & $(0.1061)$ & (0.1149) & (0.1 & $(0.1$ & (0.1 & (0.1833) \\
\hline Region Dum. Car & 0.4018 & 0.3233 & 0.3111 & 0.3487 & 0.3529 & 0.3282 & 0.3259 & 0.3724 & 0.4438 \\
\hline Driver 6 & $(0.077)$ & $(0.0702)$ & $(0.0717)$ & $(0.0726)$ & $(0.0805)$ & $\left(0 . c_{0}\right.$ & $(0.1183)$ & $(0.1223)$ & $(0.1148)$ \\
\hline Region Dum. Car & 0.612 & 0.4595 & 0.437 & 0.4088 & 0.4808 & 0.4647 & 0.5757 & 0.8059 & 0.826 \\
\hline Driver 7 & $(0.1152)$ & $(0.1)$ & (0.0954) & $(0.0944)$ & (0.1044) & $(0.1276)$ & $(0.1527)$ & $(0.1647)$ & (0.1577) \\
\hline Region Dum. & 2.5135 & 2.5317 & 2.7693 & 2.7523 & 2.7335 & 2.5452 & 2.7402 & 2.8275 & 2.7434 \\
\hline Pub 1 & $(0.13)$ & $(0.114)$ & $(0.1105)$ & $(0.1078)$ & (0.1179) & $(0.1402)$ & $(0.1646)$ & $(0.1675)$ & (0.1592) \\
\hline Region Dum. & 1.068 & 1.0708 & 1.2643 & 1.3476 & 1.4008 & 1.3281 & 1.3186 & 1.4649 & 1.4406 \\
\hline Pub 2 & (0.1049) & $(0.0941)$ & $(0.0933)$ & $(0.0924)$ & $(0.1012)$ & $(0.121)$ & $(0.1447)$ & $(0.151)$ & $(0.1446)$ \\
\hline Region Dum. & 0.3659 & 0.253 & 0.4099 & 0.3738 & 0.3641 & 0.3142 & 0.4495 & 0.6889 & 0.6765 \\
\hline Pub 3 & $(0.1215)$ & $(0.1108)$ & $(0.1059)$ & $(0.1061)$ & $(0.1151)$ & $(0.13$ & $(0.16$ & $(0.1$ & (0.1653) \\
\hline Region Dum. & 0.1484 & 0.0138 & 0.1103 & 0.1018 & 0.2014 & 0.1915 & 0.4796 & 0.3255 & 0.2025 \\
\hline Pub 4 & (0.1699) & $(0.1528)$ & $(0.1404)$ & $(0.1394)$ & $(0.152)$ & $(0.1898)$ & $(0.2272)$ & $(0.2$ & $(0.2256)$ \\
\hline Region Dum. & 0.7952 & 0.7892 & 0.8214 & 0.858 & 0.8832 & 0.7599 & 0.6732 & 0.7417 & 0.6388 \\
\hline Pub 5 & (0.1749) & $(0.1579)$ & $(0.1522)$ & $(0.145)$ & $(0.1556)$ & $(0.1808)$ & $(0.2188)$ & $(0.2379)$ & $(0.2487)$ \\
\hline Region Dum. & -0.0334 & -0.082 & 0.0878 & 0.1655 & 0.2172 & 0.1992 & 0.242 & 0.4079 & 0.312 \\
\hline Pub 6 & (0.1019) & $(0.0915)$ & $(0.0909)$ & $(0.0902)$ & $(0.0989)$ & $(0.1184)$ & $(0.1413)$ & (0.1485 & (0.1441) \\
\hline Region Dum. & 1.5377 & 1.3331 & 1.4434 & 1.5296 & 1.6213 & 1.5484 & 1.5145 & 1.8126 & 1.6068 \\
\hline Pub 7 & $(0.1326)$ & $(0.1186)$ & $(0.1127)$ & $(0.1107)$ & $(0.1206)$ & $(0.1451)$ & (0.173) & (0. & (0.1824) \\
\hline \multirow[t]{2}{*}{ Car Passenger } & -0.2885 & -0.2364 & 0.0406 & 0.18 & 0.1848 & 0.0118 & -0.0623 & 0.1339 & 0.1237 \\
\hline & $(0.0873)$ & $(0.0784)$ & $(0.0777)$ & $(0.0776)$ & $(0.085)$ & $(0.1041)$ & $(0.1236)$ & $(0.1294)$ & (0.1231) \\
\hline Age Dum. & 15.7131 & 14.536 & 5.6459 & 5.6371 & 3.8824 & 3.6709 & 3.9227 & 4.6327 & 4.6898 \\
\hline Walk 2 & $(0.0437)$ & $(0.0382)$ & $(1.0038)$ & $(1.0038)$ & (0.5094) & $(0.5145)$ & (0.7219) & $(81.271)$ & (75.917) \\
\hline Age Dum. & 3.611 & 3.0863 & 3.2526 & 3.1344 & 3.721 & 3.7728 & 4.1447 & 4.1591 & 3.9449 \\
\hline Walk 3 & $(0.3897)$ & $(0.2716)$ & $(0.2894)$ & $(0.2707)$ & $(0.3644)$ & $(0.4604)$ & $(0.723)$ & (0.5905) & (0.5139) \\
\hline Age Dum. & 15.3594 & 14.1799 & 5.3336 & 5.3839 & 3.6451 & 3.4482 & 3.6761 & 4.2952 & 4.3394 \\
\hline Bike 2 & $(0.0433)$ & $(0.0384)$ & (1.0039) & (1.0039) & $(0.5096)$ & (0.5147) & $(0.722)$ & (81.270) & (75.917) \\
\hline Age Dum. & 3.0398 & 2.4636 & 2.6533 & 2.5325 & 3.1128 & 3.173 & 3.5855 & 3.6158 & 3.3321 \\
\hline Bike 3 & $(0.3902)$ & $(0.2724)$ & $(0.2899)$ & $(0.2713)$ & $(0.3649)$ & $(0.4609)$ & $(0.7231)$ & $(0.5908)$ & $(0.5145)$ \\
\hline Age Dum. & 15.2336 & 14.1013 & 5.2605 & 5.3038 & 3.5616 & 3.383 & 3.6688 & 4.346 & 4.3365 \\
\hline Car Driver 2 & $(\mathrm{~N} / \mathrm{A})$ & (NA) & (1.004) & (1.0039) & $(0.5098)$ & $(0.515)$ & $(0.7225)$ & (81.271) & (75.918) \\
\hline Age Dum. & 2.8867 & 2.3958 & 2.6425 & 2.5505 & 3.1552 & 3.2187 & 3.6269 & 3.5999 & 3.3554 \\
\hline Car Driver 3 & $(0.3913)$ & $(0.2723)$ & $(0.2898)$ & $(0.2713)$ & $(0.3649)$ & $(0.4611)$ & $(0.7234)$ & $(0.5908)$ & $(0.5145)$ \\
\hline Age Dum. & 15.1621 & 13.9875 & 5.0648 & 5.0343 & 3.2063 & 2.9647 & 3.1771 & 3.8707 & 3.88 \\
\hline Car Pas. 2 & $(0.0486)$ & $(0.0425)$ & (1.0043) & $(1.0042)$ & $(0.5106)$ & $(0.5166)$ & (0.7239) & (81.272) & (75.919) \\
\hline Age Dum. & 3.1037 & 2.5739 & 2.744 & 2.621 & 3.1993 & 3.2738 & 3.6977 & 3.6999 & 3.4403 \\
\hline Car Pas. 3 & $(0.391)$ & $(0.2735)$ & $(0.2908)$ & $(0.2721)$ & $(0.3655)$ & $(0.4616)$ & $(0.7243)$ & (0.5919) & (0.5157) \\
\hline Age Dum. & 14.71 & 13.5304 & 4.625 & 4.6727 & 2.9683 & 2.761 & 3.0222 & 3.5734 & 3.6222 \\
\hline Pub 2 & $(0.070)$ & $(0.063)$ & $(1.0052)$ & (1.005) & $(0.5118)$ & $(0.5172)$ & $(0.725)$ & (81.265) & (75.913) \\
\hline
\end{tabular}




\begin{tabular}{llllllllll} 
Age Dum. & 2.6045 & 2.1061 & 2.275 & 2.1267 & 2.6448 & 2.6966 & 3.0756 & 3.0746 & 2.7177 \\
Pub. 3 & $(0.392)$ & $(0.2739)$ & $(0.2916)$ & $(0.273)$ & $(0.367)$ & $(0.4627)$ & $(0.7247)$ & $(0.5926)$ & $(0.5167)$ \\
Public Transport & 2.5261 & 2.4844 & 2.4218 & 2.4639 & 2.4608 & 2.4376 & 2.2532 & 2.2349 & 2.2529 \\
& $(0.049)$ & $(0.0441)$ & $(0.0402)$ & $(0.0386)$ & $(0.0418)$ & $(0.0495)$ & $(0.0577)$ & $(0.0594)$ & $(0.0588)$ \\
Driver License & 3.6546 & 3.6787 & 3.6651 & 3.6639 & 3.6518 & 3.6721 & 3.6225 & 3.6648 & 3.5407 \\
CarD & $(0.082)$ & $(0.0763)$ & $(0.0724)$ & $(0.0712)$ & $(0.0771)$ & $(0.0905)$ & $(0.1046)$ & $(0.1104)$ & $(0.1102)$ \\
Household Cars & -3.6399 & -3.7274 & -3.6553 & -3.676 & -3.7099 & -3.8043 & -3.7402 & -3.6529 & -3.4977 \\
1 CarD & $(0.095)$ & $(0.0849)$ & $(0.0776)$ & $(0.0748)$ & $(0.0816)$ & $(0.0971)$ & $(0.1103)$ & $(0.1124)$ & $(0.1085)$ \\
Household Cars & -1.3659 & -1.3673 & -1.282 & -1.2543 & -1.2375 & -1.2558 & -1.1541 & -1.0844 & -1.0818 \\
2 CarD & $(0.080)$ & $(0.0669)$ & $(0.0568)$ & $(0.0523)$ & $(0.0557)$ & $(0.0656)$ & $(0.074)$ & $(0.0767)$ & $(0.0755)$ \\
Household Cars & -0.9621 & -0.9663 & -0.8329 & -0.7746 & -0.7331 & -0.7245 & -0.6036 & -0.5825 & -0.6372 \\
3 CarD & $(0.0849)$ & $(0.0699)$ & $(0.0588)$ & $(0.0537)$ & $(0.0572)$ & $(0.0676)$ & $(0.0762)$ & $(0.0791)$ & $(0.0777)$ \\
Parking cost & -0.0996 & -0.1092 & -0.1118 & -0.1060 & -0.1053 & -0.1040 & -0.1141 & -0.1091 & -0.1058 \\
& $(0.0074)$ & $(0.0066)$ & $(0.0062)$ & $(0.0060)$ & $(0.0065)$ & $(0.0075)$ & $(0.0085)$ & $(0.0087)$ & $(0.0088)$ \\
\hline Nobs & 38014 & 49322 & 58630 & 63443 & 53154 & 37511 & 28425 & 26668 & 27200 \\
$\ell(0)$ & -68112 & -88373 & -105051 & -113675 & -95239 & -67211 & -50931 & -47783 & -48736 \\
$\ell$ & -38209 & -49890 & -59545 & -64656 & -53819 & -37742 & -28110 & -26231 & -26933 \\
$\delta^{2}$ & 0.439 & 0.435 & 0.433 & 0.431 & 0.435 & 0.438 & 0.448 & 0.451 & 0.447 \\
\hline
\end{tabular}

Table D.1: Model parameters for all models. Numbers in parenthesis represent standard errors for the model.

\section{Cross variation between VoT and income}




Figure D.1: Revealed cross-temporal variation in the VTTS with respect to income.

Change in coefficient of linear relationship between income and VoT

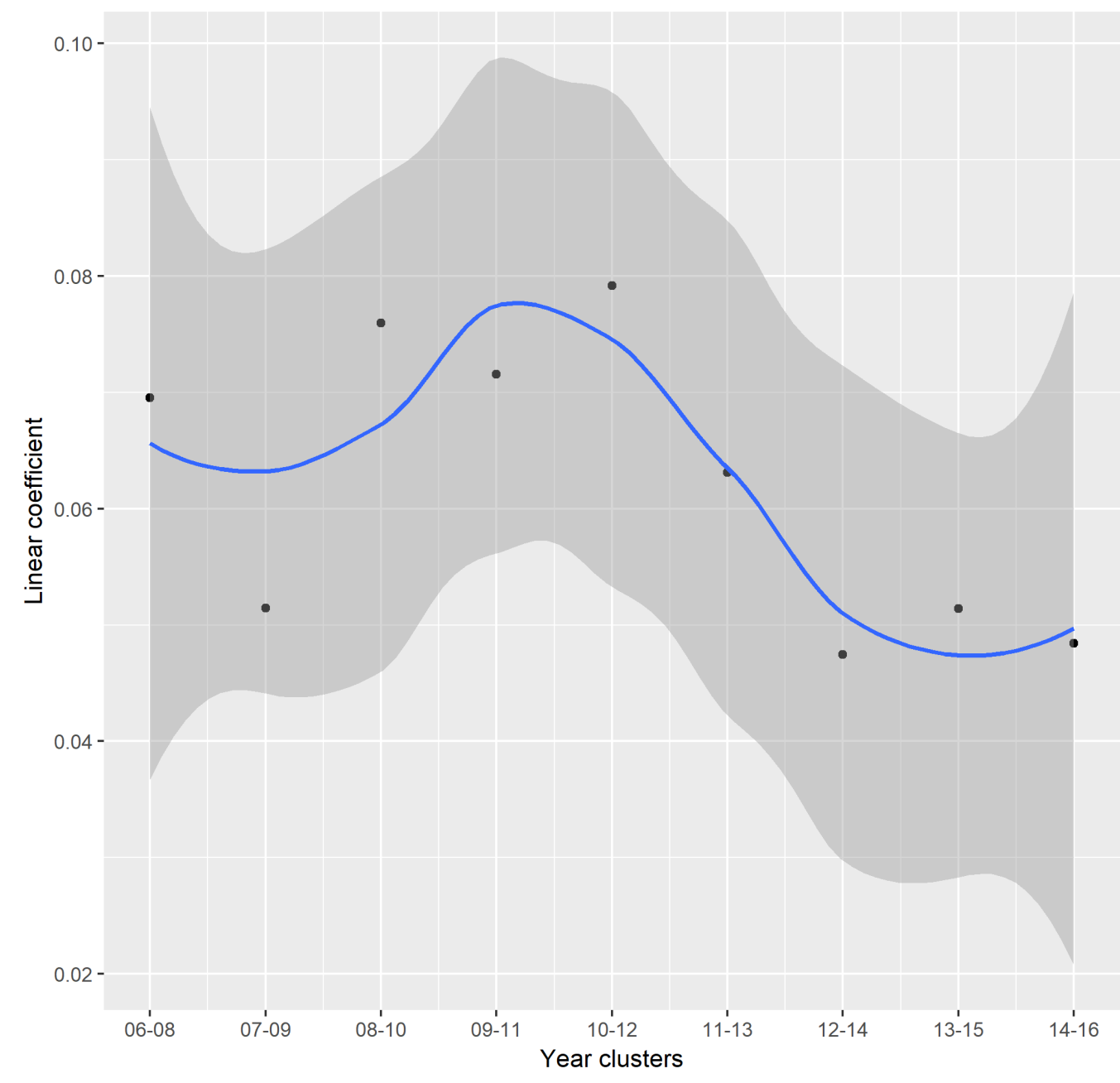

Figure D.2: Regression parameters for income and the VTTS for cross-sectional variation for different years. 